\title{
Intimidad y relaciones de pareja durante \\ la pandemia de la Covid- 19 en Guadalajara
}

\author{
Intimacy and couple relationships during \\ the covID-19 pandemic in Guadalajara
}

\author{
Tania Rodríguez Salazar• \\ Zeyda Rodríguez Morales*•
}

\begin{abstract}
Resumen
En este artículo se analizan algunos de los cambios y afectaciones que han vivido las relaciones de pareja en el Área Metropolitana de Guadalajara (México) después de un periodo de confinamiento de casi dos meses a causa de la pandemia de la Covid-19, en particular en su vida sexual y en el uso de tecnologías afectivas. Este análisis toma como principal insumo una parte de la Encuesta virtual acerca de las relaciones de pareja en el contexto de la pandemia por la covid-19. Los resultados muestran que los cambios y afectaciones en los aspectos seleccionados son más fuertes entre los jóvenes, las parejas con menos años de relación y aquellas que por el confinamiento han funcionado como parejas a distancia. Asimismo, confirman que la intimidad doméstica de tiempo completo ha implicado la recuperación de tiempo, conversación y energía para la relación de pareja, así como que los dispositivos móviles han ampliado las oportunidades de interacciones fuera del hogar y creado interferencias en la convivencia de pareja.
\end{abstract}

Palabras clave: pandemia CovID-19, intimidad, relaciones de pareja, tecnologías afectivas, sexualidad

\begin{abstract}
This article analyzes some of the changes and effects that couples have experienced in the metropolitan area of Guadalajara (México) after a period of confinement of almost two months due to the Covid-19 pandemic, particularly in their sexual life and in the use of affective technologies. This analysis is based on a Virtual Survey on romantic relationships in the context of the CovID-19 pandemic. Final outcomes will show that the changes and effects on the selected topics are stronger among young people, couples with fewer years in a relationship and those who, due to the confinement, have functioned as long-distance couples. Likewise, they will confirm that full-time domestic intimacy has implied the recovery of time, conversation and vitality for their relationships, as well as mobile devices expanding the opportunities for interactions outside home and creating interferences in the couples' interactions.
\end{abstract}

Keywords: covID-19 pandemic, intimacy, couple relationships, affective technologies, sexuality

\footnotetext{
- Este trabajo se enmarca dentro de un proyecto más amplio titulado: Intimidad y relaciones de pareja en la región centro-occidente del México contemporáneo: desafíos socioculturales, el cual es apoyado por el Fondo SEP - CONACYT con número: 245227/CB284023.

- Profesora investigadora titular C, Departamento de Estudios de la Comunicación Social, Centro Universitario de Ciencias Sociales y Humanidades, Universidad de Guadalajara. Doctora en Ciencias Sociales por la Universidad de Guadalajara. Orcid:0000-0002-9|37-6067 / tania.rs70@gmail.com - Profesora investigadora titular C, Departamento de Estudios de la Comunicación Social, Centro Universitario de Ciencias Sociales y Humanidades, Universidad de Guadalajara. Doctora en Ciencias Sociales por la Universidad de Guadalajara. Orcid:0000-0001-7003-6365 / zeydaisabel@hotmail.com Fecha de recepción: 6 de julio de 2020. Fecha de aceptación: 12 de agosto de 2020.
} 
El reto mayor es el interior. ¿Cómo vivir la vida cuando se ha quedado sin trucos defensivos ni disfraces? La vida cruda y limpia en el lento e incandescente tiempo de la peste (...) Cuando el ruido y el movimiento incesante se paran, queda lo real. Aguantar semanas con unos niños a los que normalmente aparcas en algún lado. Convivir de verdad con tu pareja en un ámbito estrecho, y aprender no solo a escucharla, sino también a respetar su ausencia en la presencia.

Rosa Montero

\section{Introducción}

La pandemia de la covID-19 ha impactado prácticamente todos los ámbitos de la vida social de las personas en gran parte del mundo. La sociedad mexicana no ha sido la excepción. La pandemia no se ha manifestado como una crisis solo del sistema sanitario en México, sino también económica, social, informativa, y, como veremos enseguida, también ha trastornado la intimidad y las relaciones de pareja. Como señala Ignacio Ramonet, se trata de lo que "las ciencias sociales califican de hecho social total, en el sentido de que convulsiona el conjunto de las relaciones sociales, y conmociona a la totalidad de los actores, de las instituciones y de los valores" (Ramonet, 2020). La pandemia ha dejado al descubierto las estructuras que gobiernan los mecanismos del mundo, tanto en términos macroestructurales: sistema económico, estructura sanitaria, precariedad laboral, etc., como en el nivel micro social, al revelar numerosas desigualdades entre las personas.

Las medidas adoptadas por el gobierno federal dispusieron el confinamiento de las personas en sus hogares bajo el llamado "Quédate en casa", como estrategia para reducir el número de contagios y la subsiguiente saturación de la capacidad hospitalaria en el país. ${ }^{1}$ Esta práctica ha generado

I.En Jalisco, la Universidad de Guadalajara ha continuado con el llamado "Quédate en casa", en abierta discrepancia con los gobiernos estatal y federal, y mantiene cerradas las actividades presenciales en todas sus instalaciones, de forma indefinida. 
una experiencia inédita que repercute en la alteración en su conjunto de la esfera de la socialidad, ${ }^{2}$ con un efecto de aislamiento social y debilitamiento de los vínculos en su dimensión presencial o cara a cara. Este encierro prolongado ha generado, sin buscarlo, una cierta "suspensión" de la aceleración del mundo contemporáneo, esa de la que habla el filósofo coreano Byung Chul-Han, cuando se refiere a la necesidad de recuperar la capacidad de contemplación en aras de observar de nuevo la densidad de la vida, su duración, de percibir el aroma del tiempo (2015). Solo que él se refería a la necesidad urgente de escapar de la tiranía del trabajo, no del riesgo de morir contagiados por un virus.

La pandemia provocó también un cúmulo de emociones difícilmente compartidas antes a escala planetaria, causadas por un mismo fenómeno social. En palabras de la filósofa Eve Illouz, uno de los principios fundamentales de la vida en la actualidad,

La libertad, el valor moderno al que se subordinan todos los demás, ha sido suspendida, no a causa de un nuevo tirano sino a causa del miedo, la emoción que se antepone a todas las demás emociones. El mundo se volvió, de la noche a la mañana, unheimlich, ${ }^{3}$ extraño, se vació de su familiaridad. Sus gestos más reconfortantes —el apretón de manos, los besos, los abrazos, la comida compartida - se transformaron en fuentes de peligro y angustia (lllouz, 2020).

El estar en confinamiento ha repercutido, en particular, en las vivencias dentro del espacio privado, la casa, el lugar donde se despliegan la intimidad y las relaciones afectivas fundamentales. Situarse en este espacio implica adentrarse en prácticas que nos acercan a los otros, en las que el cono-

2. Entendemos dentro del concepto de socialidad "los modos diversos de estar juntos que creamos en nuestra vida cotidiana, así como en aquella que crean los medios de comunicación, o que reconstruimos con plataformas tecnológicas que potencian la interacción y la participación de sus usuarios" (Rodríguez-Rodríguez, 20I3, 9). 3. Siniestro. 
cimiento mutuo es profundo y se comparten pensamientos, sentimientos y emociones, ${ }^{4}$ se organizan la economía y las tareas domésticas y reproductivas, y se proporcionan y reciben cuidados de diverso tipo; se expresan afectos en el día a día que tanto pueden ser positivos como el amor, la amistad, la empatía y la comprensión, como negativos, manifestados en tensiones, conflictos, antipatías, disputas y violencias. Las relaciones íntimas han quedado al descubierto, desnudas de las diversas capas que otros espacios sociales les proveían. El mundo en que estamos confinados se ha achicado, y al mismo tiempo se ha profundizado en su estrechez.

El objetivo de este artículo es explorar la forma como el confinamiento ha alterado la vida íntima de las parejas, en particular su vida sexual y el uso de tecnologías digitales, tomando como base los resultados de una encuesta titulada Encuesta virtual acerca de las relaciones de pareja en el contexto de la pandemia por la COVID-19. ${ }^{5}$

Partimos de una visión cultural e histórica sobre la sexualidad, y no fisiológica o morfológica; la organización social determina en gran medida las prácticas sexuales que las personas realizan, así como los significados con que son revestidas (Weeks, 1998). El advenimiento de la pandemia y la llamada al confinamiento las han trastocado. Asimismo, consideramos los medios digitales como tecnologías afectivas (Lasén, 2009) que se han instalado de lleno en nuestra vida diaria y que, en el contexto de la pandemia, han adquirido un papel protagónico para la socialidad íntima, así como en el trabajo y la educación a distancia.

La hipótesis que guía en forma general nuestra exploración sobre estos fenómenos considera que a raíz de la pan-

4. Para una revisión amplia del concepto de intimidad, ver Rodríguez et al. (2019). 5. El diseño del cuestionario fue producto de la colaboración de las integrantes del grupo de investigación del proyecto mencionado antes: doctora Zeyda Rodríguez Morales, doctora Tania Rodríguez Salazar, doctora María del Rocío Enríquez Rosas, doctora Ana Josefina Cuevas Hernández, y la becaria posdoctorante doctora Ana Gabriel Castillo Sánchez. La encuesta estuvo disponible del 2 a 10 de mayo de 2020.

\section{8}


demia las parejas no cambiaron drásticamente su dinámica, sino que la forma en que funcionaban previamente se intensificó y profundizó, marcando el rumbo tanto en un sentido positivo, cuando existía ya comunicación y entendimiento, como negativo, cuando ya había tensiones y conflictos y se desataron situaciones más ásperas, que plantean la posibilidad de la separación o divorcio y hasta la violencia. En particular, la sexualidad es uno de los aspectos más afectados por el encierro, tanto por el estrés generado por la sensación de vulnerabilidad y riesgo, como por la falta de libertad de desplazamiento y pérdida de privacidad que el confinamiento familiar supone. Por otra parte, el uso de las tecnologías de información y comunicación se intensificó a un grado nunca alcanzado antes, y reconfiguró todos los aspectos de la vida, en particular el de los afectos y la intimidad.

En el estado de Jalisco, la recomendación del "Quédate en casa" se instaló el 20 de marzo de 2020, a través de un video del gobernador Enrique Alfaro Ramírez, difundido a través de sus canales oficiales en redes sociales. Este hecho ocurrió unos días antes de que el gobierno federal hiciera el mismo llamado por intermedio de su subsecretario de Prevención y Promoción de la Salud, doctor Hugo López-Gatell Ramírez, cuando declaró la entrada a la fase II de la pandemia el 26 de marzo en el país, con la suspensión de actividades no esenciales del gobierno federal. Esto vino antecedido por la fase I a partir de enero de este año, la cual implicó la instrumentación de la denominada Jornada Nacional de Sana Distancia. ${ }^{6}$

La estrategia emprendida por el Gobernador de Jalisco fue bien vista en un inicio por la mayoría de los habitantes del estado. En una encuesta sobre habitabilidad realizada en cinco ciudades del país la última semana de abril, al

6. Para una información más amplia de la pandemia del coronavirus en México, ver: https://es.wikipedia.org/wiki/Pandemia_de_enfermedad_por_coronavirus_ de_2020_en_M\%C3\%A9xico. 
preguntar a las entrevistadas y los entrevistados si "Cree que las acciones del gobierno ante la pandemia son correctas", en el caso de Guadalajara se encontró que solo el 40\% consideraba adecuadas las acciones del gobierno federal, mientras que las acciones del gobierno estatal fueron consideradas correctas por el $75 \%$, y en el caso del gobierno municipal por el $60 \%$ (Ziccardi et al. gráfica 36$){ }^{7}$

El confinamiento dio lugar no solo a un descenso dramático de la dinámica económica, sino también al desarrollo de sentimientos de vulnerabilidad, desconcierto e incertidumbre entre las personas, tanto entre las que comparten el encierro, como entre las que no tienen corresidencia. ${ }^{8} \mathrm{La}$ casa se constituye como el lugar de refugio frente al peligro exterior, y el contacto o cercanía con quienes se tienen afectos resguarda de la amenaza de los extraños. Las maneras específicas de la gestión de estos asuntos entre los miembros de las familias y de las parejas configuran en gran medida el que la experiencia del confinamiento resulte placentera y agradable o devastadora.

7. Pasadas las primeras semanas, esta aprobación comenzó a declinar, como lo muestra la Encuesta de percepción y experiencia de la población del Área Metropolitana de Guadalajara (AMG) en torno a la covID-19, que compara datos venidos de sondeos telefónicos levantados en abril y mayo. En ellos se preguntó: ¿Qué tan de acuerdo está usted con las medidas que ha tomado (...) durante la contingencia? Para el gobierno de México resultó que la opción de respuesta "Muy de acuerdo" bajó de 41.3\% a $32.9 \%$, y para el gobierno de Jalisco de $54.9 \%$ a $45.7 \%$ (Observatorio ciudadano Jalisco, “Cómo vamos”, p. 2I).Asimismo, se preguntó: ¿Se ha quedado en casa todo el tiempo?,y resultó que disminuyó de $41.5 \%$ a 34.I\% en este mismo período (p. I5). 8.A escala nacional, la empresa encuestadora Consulta Mitofsky preguntó:"durante estos días en los que hemos estado más tiempo en casa, ¿Qué tanto dirías que has experimentado los siguientes sentimientos?". Resultó que respondieron con la opción “Mucho/Algo”, los siguientes: Preocupación 74\%,Tranquilidad/Paz 68.7\%, Aburrimiento 52.2\%,Ansiedad 49. I\%, Irritabilidad/Enojo 33.3\%,y Depresión 24.7\% (Consulta Mitofsky, mayo, 2020). 
Intimidad y relaciones de pareja durante la pandemia de la COVID-19 en Guadalajara

Las encuestas por Internet: cuestionario, muestra intencional y análisis

La práctica de realizar encuestas por Internet no era muy común en nuestro país, pero a lo largo de esta pandemia hemos visto su proliferación a partir de la suspensión de la realización de censos y encuestas dispuesta por el gobierno federal (INEGI, 2020). Las encuestas virtuales poseen diversas ventajas, registradas sobre todo en experiencias en países europeos y Estados Unidos: ${ }^{9}$ rapidez en el lanzamiento y captación de respuestas, muy bajo o nulo costo, cuestionarios atractivos gráficamente, procesamiento de la información casi automático, y un elemento en particular valioso, que su respuesta ocurre sin la presencia de un encuestador que pudiera inhibir o perfilar el sentido de esta en temas de la vida privada.

El objetivo de la encuesta virtual de la cual se origina este trabajo fue identificar los cambios en las relaciones de pareja en medio de la situación de confinamiento durante la pandemia de la covid-19. ${ }^{10}$ Una vez lanzada, nos sorprendió su ritmo acelerado de respuesta, pues en 24 horas se recibieron 850 de los $1,553^{11}$ cuestionarios que obtuvimos al final de la semana. Nos pareció que la encuesta despertó el interés por la temática tratada, lo cual revelaba la necesidad de la gente por expresar su experiencia respecto de sus relaciones de pareja durante la pandemia, y confirmaba

9. Un estado del arte al respecto es el de Frippiat, Marquis yWiles-Portier (2010). 10.A mediados del mes de julio, fecha en que trabajamos este texto, no se ha podido definir con claridad el término de la pandemia,y se ha generado un relajamiento de la disciplina inicial para respetar el confinamiento. Las instrucciones contradictorias entre el gobierno federal y el estatal han provocado que las personas comiencen a decidir de forma individualizada si quedarse o no en casa. El haber realizado la encuesta del 2 al 10 de mayo fue una decisión acertada, en el sentido de que el confinamiento, en gran medida, aún era respetado. Se calcula que en ese momento era de un $60 \%$, cosa que coincide con la aceptación que la llamada a "quedarse en casa" registró entre la población de Guadalajara

II.De estos, solo I,406 fueron casos válidos, es decir mayores de edad, mexicanos y que tuvieran una relación de pareja, corresidente o no, al momento de la encuesta. 
que, como señalan algunos autores, los temas delicados son mejor recibidos en encuestas donde el espacio privado es más seguro (entorno digital), se garantiza de mejor forma el anonimato y no hay presencia del encuestador, con quien pudiera ocurrir una inducción a cierto tipo de respuesta o un afán de corrección moral en ella (Díaz de Rada, 2010 y 2012).

El cuestionario consideró cinco ejes, aunque en este artículo solamente analizamos los relativos a algunas dinámicas de la vida de las parejas, la sexualidad y los usos de tecnologías, dejando fuera lo relativo a los roles de género y los cuidados entre la pareja. Las preguntas consideradas para este artículo fueron en los aspectos siguientes: i) cambios en la relación de pareja, ii) tensiones y conflictos de pareja y razones de estos, iii) posibilidad de divorciarse y motivos, iv) percepciones de cambios en la vida sexual y razones de ellos v) interferencias tecnológicas en la convivencia en pareja, y vi) discusiones o conflictos en la pareja por sus actividades en Internet. Todas las preguntas quedaron enmarcadas en el contexto de la pandemia.

El cuestionario estuvo integrado por preguntas dicotómicas, de opción múltiple (una sola respuesta), de respuesta múltiple (máximo tres o cinco respuestas) y preguntas abiertas. Fue diagramado como formulario de Google sin requerir autentificación para su respuesta, por lo que fue respondido de manera anónima. La invitación a contestar la encuesta circuló por las listas de contactos en WhatsApp y correo electrónico del grupo de investigadoras que implicaron sus redes laborales, familiares, de amistad, cívicas y de conocidos. Adicionalmente, el cuestionario tuvo un impulso posterior de parte de quienes lo contestaron y lo compartieron en sus propias redes y canales de comunicación. La muestra, en este sentido, es autoseleccionada: los receptores de la invitación decidieron participar o no como respondientes. Solamente se consideraron tres criterios de inclusión: residir en México, ser mayores de edad y tener 
una pareja de cualquier tipo al momento de la encuesta. Cuando el respondiente no cumplía con los dos últimos criterios, no se abría el resto del cuestionario. ${ }^{12}$ Cabe destacar que asumimos desde un principio que los resultados generados por este tipo de muestras no son representativos de poblaciones amplias y, por tanto, su validez externa es muy limitada (De Marchis, 2012). No obstante, consideramos que los resultados generados son igualmente valiosos y nos hablan de las experiencias de sectores de la población más o menos definidos, como veremos enseguida.

Tomando como universo el conjunto de cuestionarios válidos $(n=1406)$ que fueron respondidos por mexicanos de distintos estados de la República, configuramos una muestra intencional acotada al Área Metropolitana de Guadalajara (que fue la que concentró el mayor número de cuestionarios respondidos). La muestra sobre la que registramos datos fue, entonces, un subconjunto de 760 casos de respondientes que residen en los cuatro municipios principales (Guadalajara, Zapopan, Tonalá y Tlaquepaque) del Área Metropolitana de Guadalajara. En dicha muestra, el cuestionario virtual fue respondido principalmente por mujeres (71.7\%), con una edad promedio de 41 años. ${ }^{13}$ En cuanto a su pertenencia a cierto nivel socioeconómico, sobresalen varios factores: que fueron personas de muy alta escolaridad (95\% entre licenciatura y posgrado); con acceso a Internet fijo y móvil por medio de telefonía celular y computadoras; con un ingreso suficiente para ser poseedores de una casa propia pagada o en proceso de pago (65.4\%) y tender a no informar afectaciones a su situación financiera

12. En una revisión posterior fueron eliminados del universo de cuestionarios respondidos los de personas residentes en el extranjero.

13. Una respuesta feminizada que puede deberse a que hay mayor interés de parte de las mujeres para hablar de estos temas, y que contrasta con la tendencia a ser hombres quienes más contestan encuestas por Internet, según señalan Blasius y Brandt (2010) en el contexto alemán. 
durante la pandemia (65.8\%). ${ }^{14}$ Asimismo, el 42.5\% de ellos son empleados (probablemente con un sueldo garantizado durante la pandemia), el 14\% son estudiantes (una proporción con apoyo de beca por estar en posgrados), el 14\% son trabajadores independientes, el 10.2\% amas de casa, el 7.3\% patrones o empresarios, y menos de 1\% desempleados. Este conjunto de factores nos señala que se trata, en su mayoría, de una muestra de nivel socioeconómico medio y medio alto que, en dos terceras partes al menos, ha conservado cierta calidad de vida a lo largo del confinamiento. Con respecto a la situación de pareja y familiar, los respondientes fueron predominantemente heterosexuales $(92.5 \%)$, casados o unidos (72.6\%), en parejas con residencia en común (73.4\%), que han permanecido juntas cinco o más años (68.2\%), con hijos (58.3\%), y con un promedio de dos hijos. ${ }^{15}$ Asimismo, el número promedio de personas en la casa es de tres, por lo que no sufren hacinamiento.

Las características de la población que se autoseleccionó para responder la encuesta ponen de manifiesto la afinidad y la sensibilidad de los grupos que sobresalen con la temática, y denota su voluntad por reflexionar sobre su propia experiencia. ${ }^{16}$ Parecería que tienen las condiciones necesarias e indispensables para la autorreflexión: “...dentro de este aburrimiento y tiempos largos reflexiona uno sobre su vida, sobre lo que ha hecho, lo que uno es o quiere ser",

14.Al preguntar sobre si durante la pandemia ha cambiado su situación financiera, el $53.3 \%$ respondió que permaneció igual, el I 2.5\% que había mejorado,y el $34.2 \%$ que había empeorado.

I5. Es común que en este tipo de encuestas la población de adultos mayores sea muy baja, $y$, en estratos socioeconómicos bajos nula, como también encontraron Blasius y Brandt (20I0) en el contexto alemán.

16. Cabe señalar que el perfil de las personas que respondieron la encuesta en línea sobre sexualidad realizada por la Asociación Mexicana para la Salud Sexual, y con la cual realizaremos diversas comparaciones, presenta enormes similitudes con el nuestro: es una respuesta feminizada ( $66 \%$ mujeres $/ 34 \%$ hombres); con nivel educativo alto (superior $5 \mathrm{I} \%$ y de posgrado $32 \%$ ); asalariados del sector público (24.5\%), del sector privado (22.4\%) y profesional autónomo (22. I\%); clase mediabaja (54\%) y media alta (40\%), con una edad promedio de 40 años (AMSSAC, 2020). 
como señala el psicólogo social Pablo Fernández en una entrevista reciente (Israde, 2020).

Los datos aportados por las preguntas elegidas para este artículo fueron analizados con estadística descriptiva básica: tablas de frecuencia y de contingencia. Se procesaron cruces de las preguntas con las variables independientes (nominales y ordinales): sexo, grupos de edad (jóvenes, adultos medios y mayores), situación de corresidencia y años de relación de pareja (menos de diez años y diez años o más). Las comparaciones se realizaron considerando la distribución de porcentajes en columnas (justamente porque el número de casos no fue el mismo en las variables consideradas como independientes) y los valores de significación $(p)$ en una prueba de chi cuadrada para inferir que las diferencias no se deben al azar. En las gráficas presentamos resultados con una significación (p) igual o menor a .05*, $.01^{* *}$ y $.001^{* * *}$. En el caso de las preguntas con respuesta múltiple no se consideró esta prueba; se presenta la distribución de porcentajes de los encuestados que eligieron cada opción de respuesta. Estas preguntas, como sabemos, no suman 100, porque admitieron hasta cinco respuestas por cada uno de los respondientes. ${ }^{17}$ Como estrategia complementaria, ubicamos datos provenientes de otras encuestas, anteriores o realizadas durante la pandemia, con las que confrontamos nuestros resultados en aras de afianzar una interpretación sobre las relaciones de pareja en el contexto de la pandemia actual. ${ }^{18}$

17. En la reestructuración de la base de datos y en el análisis de la información colaboró con las autoras la licenciada Nora del Rosario López Mascorro, a quien agradecemos su trabajo.

18. Las posibilidades de comparación con encuestas realizadas antes de la pandemia que nos permitieran un contraste más claro fueron escasas. En el caso de información sobre prácticas sexuales en nuestro país no existe información amplia y suficiente, y lo que se encuentra disponible son preguntas aisladas en diversas encuestas, entre las que son frecuentes las enfocadas en el inicio de la vida sexual, la fecundidad y la salud sexual y reproductiva (ENJUVE, ENDIREH y ENADID). Con respecto a las encuestas disponibles sobre medios digitales e Internet, 
Las relaciones de pareja en el confinamiento

La situación de confinamiento y la calidad de la vida que es posible durante su duración dependen, en primer término, del tipo de condiciones de habitabilidad que posee la vivienda donde las parejas viven. Esto constituye la base de una convivencia más sana en todo sentido, como describen Alicia Ziccardi y colaboradores:

...para quedarse en la casa hay que tener una casa, $y$ esta debe tener condiciones de habitabilidad adecuadas según las características de la familia o las personas que la habitan (...) se debe considerar el número de miembros, las edades, el sexo, las actividades económicas y escolares de diferente nivel educativo, la disponibilidad de computadoras, la conectividad en Internet, el servicio de telefonía fija y móvil, entre otros bienes básicos (Ziccardi et al. 2020, pp. 6-7).

La situación de confinamiento que nos informaron los respondientes es que la mayoría de ellos se ha quedado en casa durante la pandemia (87.6\%), mientras que una menor parte ha tenido que salir a su lugar de trabajo (10.9\%), seguida de otra parte que ha alternado periodos de quedarse en casa con salidas laborales (1.3\%). Con respecto a lo que ocurre con sus parejas, la mayor parte observó que su pareja se ha quedado en casa (70.9\%), seguida de la opción de salir a trabajar a su lugar de trabajo (26.3\%) y finalmente de la opción de alternar periodos de quedarse en casa con salir a trabajar (2\%). Los respondientes de nuestra encuesta informaron que la mayor parte de las parejas compartió la residencia (73.4\%), pero un poco más de un cuarto, el $26.6 \%$, no es corresidente. Los retos que implica cada situación fueron distintos. Las parejas corresidentes tuvieron que ajustarse a estar veinticuatro horas al día, siete días de la 
semana, juntos en una vivienda dentro de la cual tuvieron que definir zonas de espacio compartido y otras de espacio privado, así fueran algunas horas o minutos al día.

La forma de organización de las parejas se revela en las rutinas que llevan a cabo y, en el caso del período de confinamiento, en la exploración sobre si tales rutinas han cambiado. Llama la atención que el 57.1\% de los encuestados informó que colaboran entre ambos para hacer cosas juntos, lo cual expresa un alto índice de compenetración entre ellos, y casi en la misma proporción responden que tienen más tiempo para platicar y convivir (56.1\%). Esto se combina con que el $46.8 \%$ conserva espacios de actividad independiente, lo cual denota respeto por la individualidad en casi la mitad de los casos. En un sentido opuesto aparece que el propio encuestado (36.8\%) y su pareja $(31.7 \%)$ pasan demasiado tiempo en Internet, trabajan más que antes (21.2\%), y discuten más y con mayor frecuencia (15.1\%). Estos cambios en las rutinas de pareja, no obstante, difieren en la frecuencia de selección por parte de los encuestados, en función de si viven junto a su pareja o viven separados (gráfica 1).

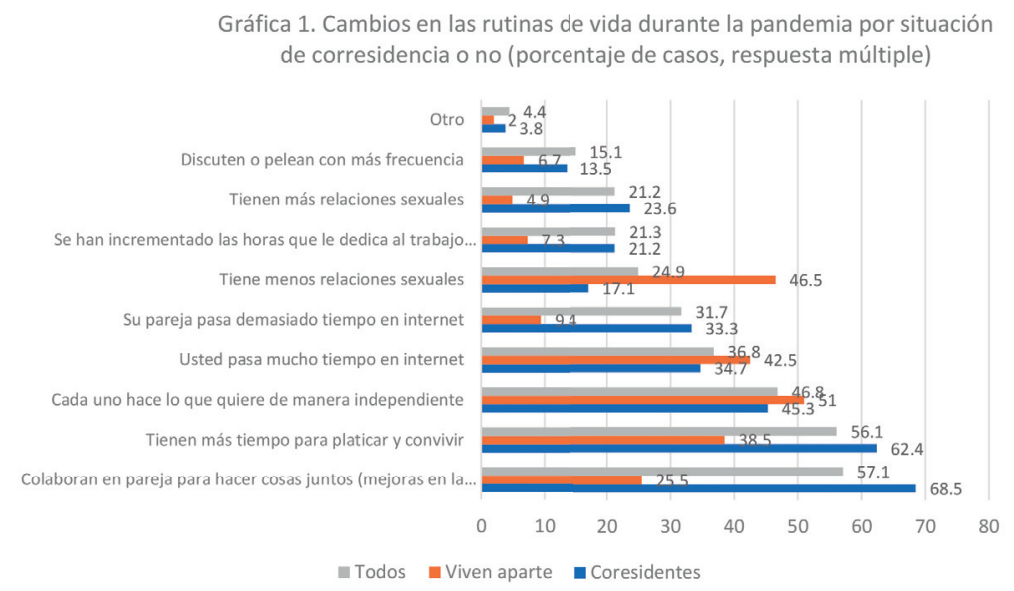

Sociedad No.78-79 
Uno de los retos de las parejas que viven en corresidencia, como indicamos antes, es estar compartiendo el espacio de manera ininterrumpida; esto podría generar, por una parte, la disminución o desaparición de espacios privados, y, por la otra, una mutua y continua observancia y un monitoreo de las actividades del otro, lo cual limita la independencia y podría dar pie al acoso u hostigamiento mutuo. En términos de las necesidades afectivas, la disminución o desaparición de interacciones presenciales con otras personas deriva en la limitación de acceso a círculos de socialidad presenciales alternativos a la propia pareja y la familia nuclear, tales como amistades, familia extensa, compañeros de trabajo, etc. En ese sentido, el encierro por la pandemia incrementa la exigencia hacia la pareja para satisfacer la afectividad propia, al no poderse acceder a las gratificaciones obtenidas al ir a la escuela, al trabajo o salir a la calle. Las necesidades dejan de ser satisfechas por una gran pluralidad de personas y concentran su demanda en unas cuantas, la principal, su pareja. En ese proceso, es posible que muchas personas se encuentren con sentimientos ligados a la depresión, la melancolía o la frustración, lo que puede llegar a generar conflictos en la pareja donde antes no los había.

Entre los encuestados, el haber tenido tensiones o conflictos ocurrió en el 51.8\%; es decir, la mitad de ellos. Dentro de quienes manifestaron esta situación $(n=394)$, son las mujeres quienes registran con más frecuencia vivir tensiones o conflictos con sus parejas (54.9\%), con respecto a los hombres (44.2\%). Asimismo, son los adultos jóvenes (58.9\%) quienes informan más tensiones o conflictos con su pareja, seguidos por los adultos medios (48.7\%) y finalmente los adultos mayores (39.8\%). También las parejas con mayor número de años juntos enfrentan mejor el confinamiento que las parejas con menor número de años. En estas últimas apareció más el conflicto (55.5\%), por lo que parece que las de mayor duración están siendo más hábiles para 
mantener su bienestar o mejorar sus experiencias en el encierro (gráfica 2).

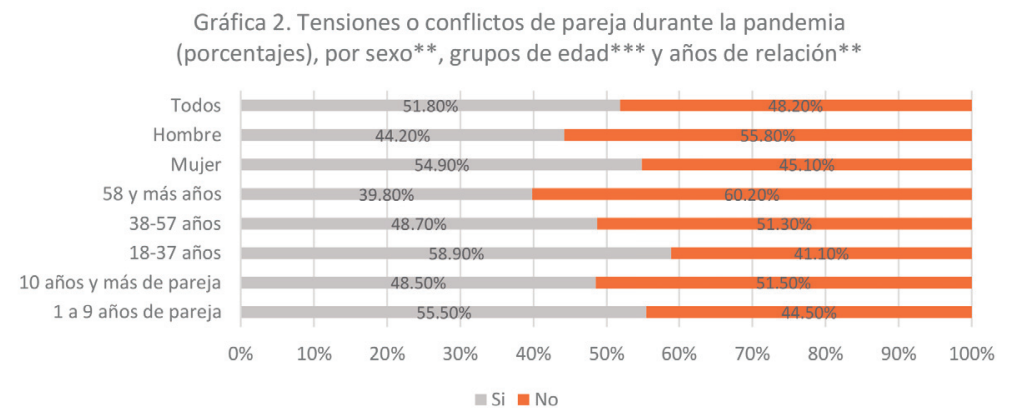

La razón más sobresaliente para haber tenido conflictos fue estrés por el encierro, tensión venida desde fuera de la pareja misma, seleccionada por el $58.4 \%$ de los respondientes, seguida de lejos por las opciones del tiempo que su pareja pasa en el celular, falta de temas comunes de conversación, diferencias frente a lo que es correcto hacer o no durante la pandemia, entre otras respuestas con frecuencias menores (gráfica 3). Es evidente que la situación de confinamiento ha marcado su impronta en la dinámica de las parejas de los estratos que predominan en la muestra estudiada, tanto en términos de estrés como de discusiones sobre cuál es el comportamiento más adecuado para enfrentar la pandemia en la vida cotidiana. 
Gráfica 3. Razones de tensiones o conflictos en pareja durante el periodo de quedarse en casa (respuesta múltiple, porcentajes)

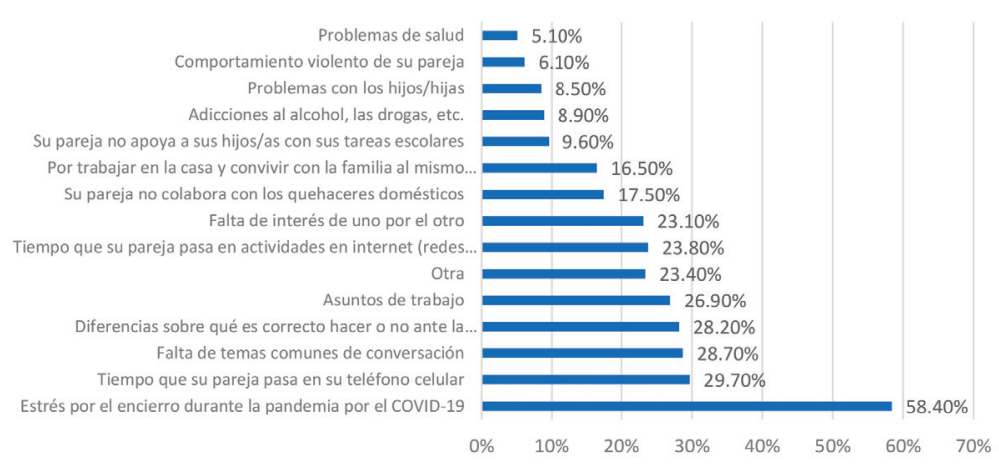

Un elemento más sobre la dinámica de las parejas durante el confinamiento es la pregunta sobre si se han planteado separarse o divorciarse en este período, a la que el 23.3\% respondió afirmativamente. Este dato es muy alto, se podría pensar que casi la cuarta parte de los respondientes considera que los conflictos o tensiones vividos ameritan considerar la separación o el divorcio, lo cual hace pensar que se trata de conflictos graves que ya venían gestándose tiempo atrás y que fueron agudizados por el encierro.

El confinamiento coloca a la pareja frente a un espejo donde se ve desnuda. Sin las actividades fuera de casa, las interacciones en círculos de amistad, laborales y familiares, las parejas se quedan solas, y sus problemas aparecen nítidamente, lo que hace imposible ignorarlos. El motivo más seleccionado entre quienes admitieron haber pensado en el divorcio o separación $(n=177)$ fue la falta de comunicación, con un $53.1 \%$ a la cual podríamos juntar con las diferencias de intereses y objetivos, mencionada por el 33.8\%. En este sentido, el conjunto con mayor porcentaje se refiere a parejas que permanecían juntas por inercia, que ya no comparten los elementos fundamentales de la unión, como la comunicación y el proyecto en común. A esto se une un tercer conjunto donde aparece el desamor, en el $26.9 \%$, y la

\section{0}


desaparición de la pasión sexual, en el $24.6 \%$, elementos que remiten a la caducidad del sentimiento amoroso y el deseo. Enseguida y a pesar de estar confinados, los encuestados refieren la aparición de una nueva persona en el 35.4\%, los celos en el $14.6 \%$ y la infidelidad en el $9.2 \%$, asuntos que aluden a la crisis de la pareja por la violación del principio de la monogamia, tan caro al imaginario romántico y amenaza tradicional a las parejas establecidas. Por último, esta convivencia intensificada del confinamiento produce excesivo control para el 17.7\%, y comportamientos violentos y maltrato en el 19.2\% (gráfica 4).

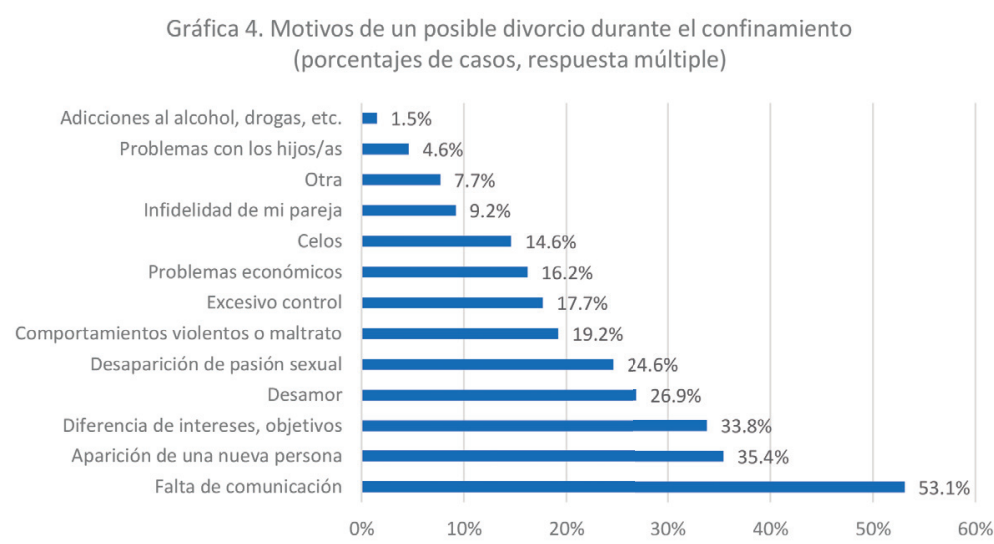

En varios artículos sobre los conflictos en las parejas durante la pandemia se ha mencionado el caso de la ciudad china de Xi'an, donde se registró un número histórico de solicitudes de divorcio, "A causa de la epidemia, muchas parejas han estado juntas en casa durante más de un mes, lo que sacó a la superficie conflictos que permanecían escondidos", explicaba un funcionario local a una revista (Infobae, marzo 2020). Este fenómeno ha sido denominado covidivorcio. 


\section{La sexualidad presencial}

Como planteamos al inicio, la sexualidad es un aspecto de la vida de los individuos atravesado por dinámicas sociales; en este caso, el confinamiento de las parejas. En principio, resulta interesante dar cuenta de las suposiciones que desde el sentido común han circulado en torno a la vida sexual durante la pandemia. Al inicio de esta etapa, en algunos países de Europa se rumoró que luego de nueve meses de ocurrida habría un boom de nacimientos por una intensificación de la actividad sexual en el encierro (Infobae, marzo, 2020). Tal aseveración tiene eco en la preeminencia de cierto imaginario contemporáneo en el que la sexualidad se ha colocado al centro, como afirma Serge Chaumier, "el erotismo aumenta en todos lados (...) El sexo se utiliza públicamente como moneda de cambio de la imaginación contemporánea, hasta el punto de que hablamos de pornografismo" (2006, p. 223). Los ideales de placer y vida romántica aparecen en cada película y anuncio publicitario, libros de autoayuda y programas de televisión. No obstante, y aun antes de la pandemia, nos encontramos situados en un mundo hipersexualizado que no necesariamente se corresponde con las prácticas reales. Como sostenemos en este trabajo, la pandemia y el confinamiento han dejado al descubierto las estructuras que subyacen a la vida íntima, y los datos arrojados en nuestra encuesta dibujan justamente los contornos de la vida sexual en las parejas, cuestionando profundamente la posibilidad real de que se estén dedicando a enriquecer sus placeres.

En la encuesta hicimos un conjunto de preguntas para valorar si algunos aspectos de la vida personal habían empeorado, mejorado o permanecido igual durante la pandemia. Con respecto a su vida sexual, los encuestados respondieron que permaneció igual para el 54.8\% de la muestra total. No obstante, al comparar por grupos de edad,

\section{2}


la respuesta de permaneció igual fue más clara para los adultos mayores con un $72.7 \%$, dato que decreció para los adultos medios con un $62.6 \%$, mientras que para los jóvenes solo fue de un $40.7 \%$. Esta tendencia se refuerza al ver las variaciones por años de vida en común, pues la vida sexual permaneció igual en mayor medida para los de diez años o más (62.4\%), mientras que para los que tienen menos de diez años de relación fue menor (46.3\%).

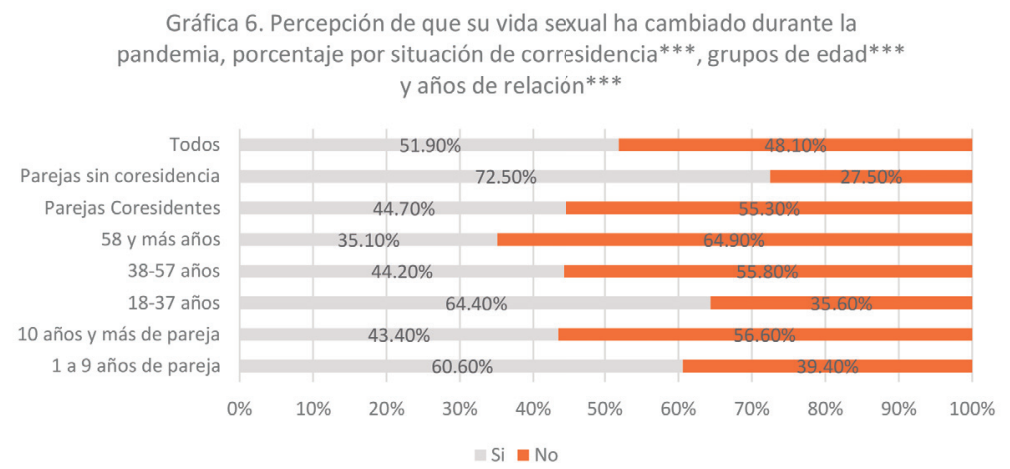

Con respecto a la percepción de que durante el confinamiento la vida sexual empeoró, observamos la frecuencia más alta en quienes tienen parejas sin corresidencia, tienen relaciones de menos de diez años y son jóvenes adultos. No encontramos diferencias por sexo. A partir de este primer acercamiento, se dibuja una tendencia clara en nuestros resultados, el grupo de los jóvenes es el que más ha visto afectada su vida sexual, en concordancia con ser ellos quienes tienen menor cantidad de años de vida en común y quienes más están implicados en relaciones sin corresidencia. ${ }^{19}$

Con la misma intención de explorar los cambios en la vida sexual, se formuló una pregunta directa sobre si han vivido

19. Es importante señalar que entre ellos es frecuente la situación de no corresidencia por no estar unidos o casados, fenómeno que tiene que ver con que el grupo de jóvenes ampara un rango de edad entre 18 y 37 años. 
o no cambios en este aspecto, a lo que los encuestados respondieron sí en el 51.9\%, y no el 48.1\%. ${ }^{20}$ En esta pregunta, los resultados convergen claramente con los presentados en la gráfica 5: los grupos que informan con más frecuencia que su vida sexual cambió fueron quienes tienen parejas sin corresidencia, los jóvenes adultos y los que tienen relaciones de pareja con menos de diez años de duración.

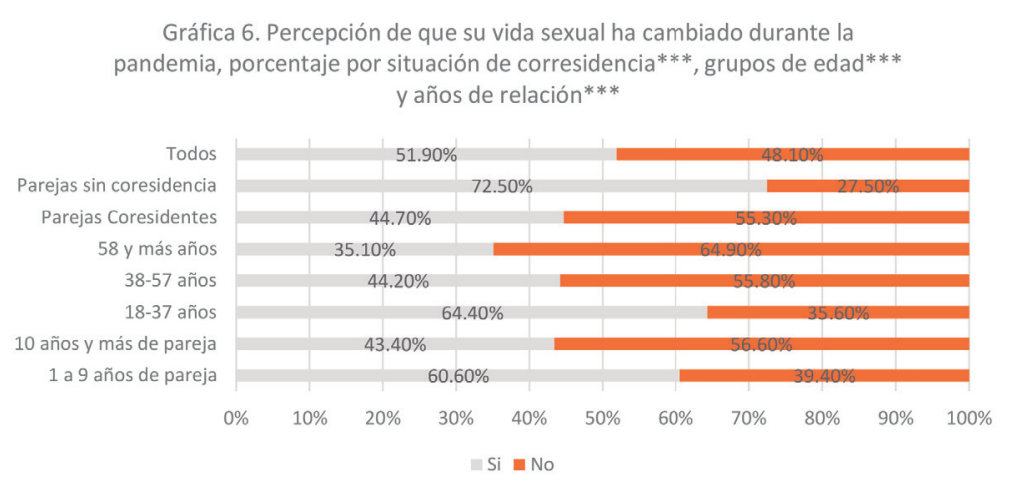

De manera específica, podemos observar que, entre quienes respondieron que sí cambió su vida sexual $(n=358)$ en términos negativos, sobresale, en primer lugar, la disminución de la privacidad (31.8\%); en segundo, el aumento del estrés (29.3\%); en tercero, el mayor cansancio (21.8\%), y, en cuarto, nunca estar solos (20.9\%). En contraste, los cuatro lugares destacados para las respuestas de cambios positivos fueron: primero, tener más tiempo (31\%); segundo, conversar sobre la vida sexual (30.4\%), tercero, tener más energía (21.2\%) y, cuarto, explorar prácticas sexuales nuevas (19\%). $\mathrm{Al}$ observar la distinción por sexo, las mujeres destacaron

20. Esta tendencia está en consonancia con los resultados de la encuesta realizada por la Asociación Mexicana para la Salud Sexual, que preguntó sobre si había habido cambios en su vida sexual durante la pandemia y la mayor parte de participantes; el $52.7 \%$, respondió que no había cambiado su patrón de conducta sexual, frente al $43.08 \%$, que informó que había disminuido y solo el $4.14 \%$ dijo que había aumentado (AMSSAC, 2020, p. 2). 
el tener menos privacidad (34.1\% vs $25.8 \%$ de los hombres) y el no estar solos ( $23 \%$ vs $15.5 \%$ de los hombres), frente a los hombres que señalaron en mayor medida tener más energía (28.9\% vs $18.4 \%$ de las mujeres) y explorar prácticas nuevas (25.8\% vs $16.5 \%$ de las mujeres). Como vemos, es posible que el que la pareja se encuentre sola y encerrada permite mayores espacios de convivencia y diálogo que para las mujeres proveen mayor disfrute como complemento a la práctica sexual. Observando los datos por duración de años de vida en común, se destaca que los que tienen más de diez años juntos responden tener más energía (25.7\% vs 18\%), tener más tiempo (36.2\% vs $27.2 \%)$, y estar más cansados (30.9\% vs 15\%), mientras que los de menos de diez años juntos conversan más sobre su vida sexual (37.9\% vs 20.4\%) y exploran prácticas sexuales nuevas (22.8\% vs $13.8 \%$ ). Es evidente que, así como el grupo de jóvenes es el más afectado en su vida sexual, al mismo tiempo es el que más relevancia le otorga concediéndole atención y creatividad (gráfica 7).

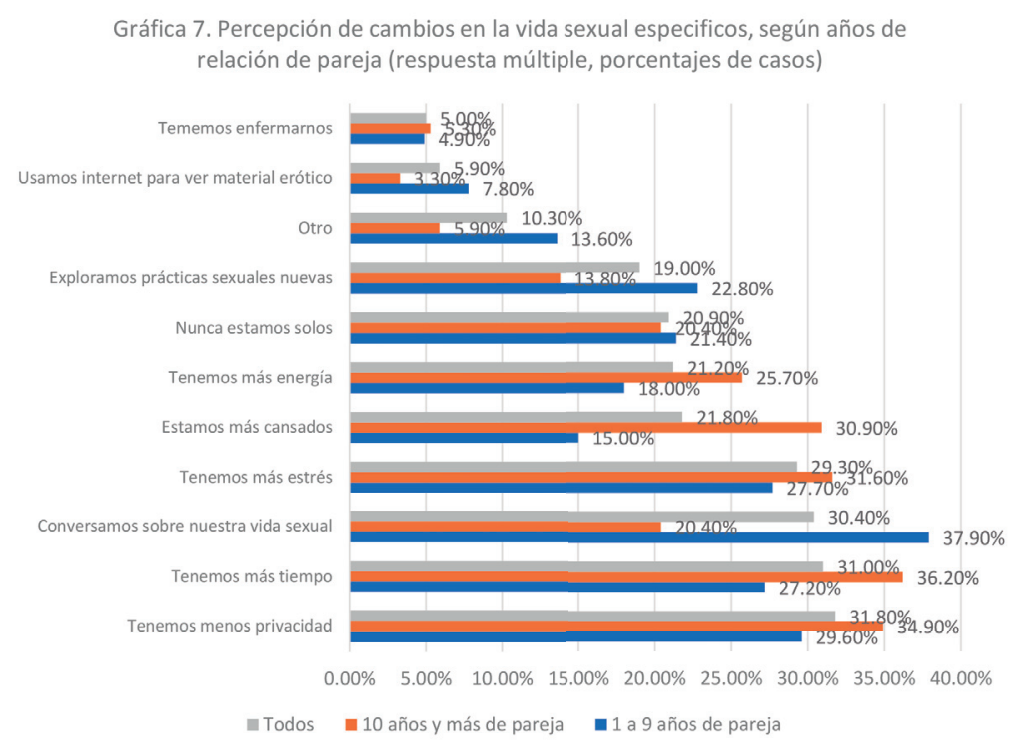

Sociedad No.78-79 
El aspecto del aumento o disminución de las relaciones sexuales no fue ponderado en una pregunta directa, sino dentro de una pregunta más general sobre los cambios experimentados en las rutinas de vida, de manera que este resultado no implica una estimación del aumento o decremento del número de relaciones, sino más bien de la importancia que le otorgaron los encuestados al aspecto sexual cuando se les preguntó sobre los cambios más importantes experimentados durante el confinamiento en sus rutinas de pareja. De la muestra total, encontramos que, en general, el $24.9 \%$ seleccionó la respuesta tener menos relaciones sexuales durante el confinamiento, y el 21.2\% tener más relaciones sexuales, en el marco de un conjunto de diez respuestas predefinidas (gráfica 1).

Con todo y las variaciones que han experimentado las parejas en su vida sexual, el hecho de vivir juntos les reporta ventajas innegables, pues, además, de mantener la posibilidad de una vida sexual activa y no mediada tecnológicamente, acusan cambios con mayor frecuencia de carácter positivo, más que la contraparte de quienes no viven con sus parejas. Prueba de esto es que para el 33.8\% de quienes corresiden ( $v$ s $18.8 \%$ de quienes viven aparte) ha mejorado el grado de satisfacción con su pareja (gráfica 8), el 25\% (vs $14.5 \%$ de su contraparte) ha mejorado su bienestar personal (gráfica 9), y, como habíamos visto antes, el 20.7\% (vs $9.4 \%$ de quienes no viven juntos) ha mejorado su vida sexual (gráfica 5). En contraste, si observamos los datos por grupos de edad, encontramos que en el caso de los jóvenes y los adultos medios se arroja un mayor porcentaje para la opción empeoró, con el $21 \%$ y el $17.3 \%$ respectivamente, frente al $10.8 \%$ de los adultos mayores para la satisfacción en su relación de pareja (gráfica 8); la misma tendencia se observa con relación al bienestar personal: la percepción de que ha empeorado es más clara en los jóvenes (37.1\%),

\section{6}


seguida por los adultos medios (27.8\%) y los mayores (17.4\%) (gráfica 9).

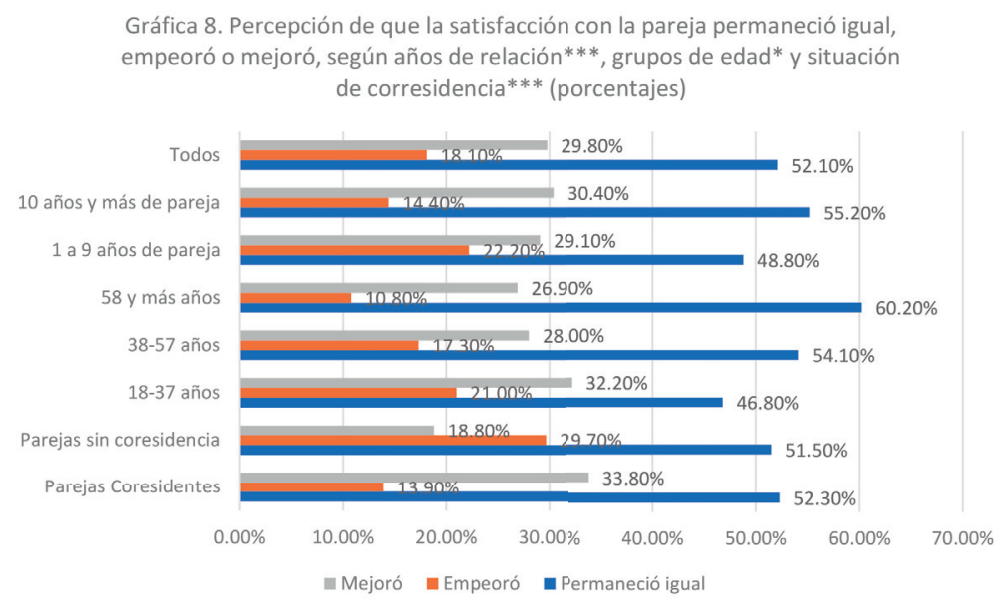

Una veta posible de análisis respecto de los beneficios generados por el confinamiento entre parejas corresidentes tiene que ver con la variación en el ritmo del tiempo cotidiano, lo que ha significado mayor convivencia, más actividades en común, flexibilización de los horarios, eliminación del tiempo invertido en los traslados por la ciudad, mayor posibilidad para conversar, cierta "suspensión" de la aceleración del mundo contemporáneo a que hicimos referencia al inicio de este texto, parafraseando a Byung Chul-Han (2015). 


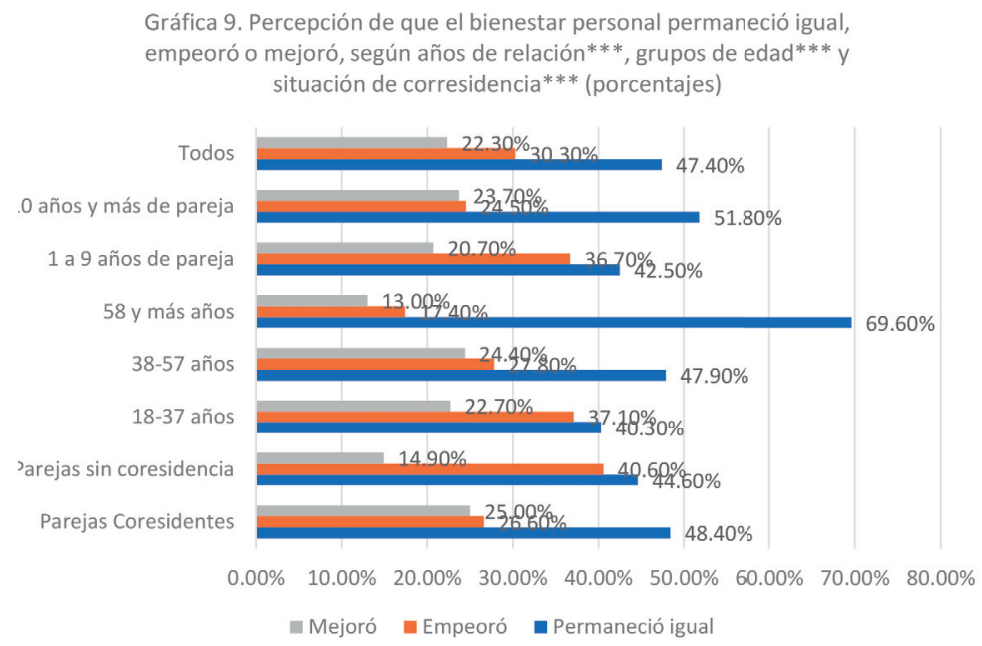

La digitalización de la vida pública y privada

Durante la pandemia, las tecnologías han profundizado la mediación que venían haciendo de la información, la comunicación, el entretenimiento y las emociones, ${ }^{21}$ pero también se han instalado de lleno en ámbitos que se resistían a incorporarlas: el trabajo (en ciertos sectores de la economía), la educación formal en prácticamente todos sus niveles de enseñanza, las reuniones familiares y convivencia entre amigos a través de las videollamadas, entre otros más. Estos usos intensivos, novedosos y forzosos de las tecnologías durante el periodo de "quedarse en casa" muestran que, efectivamente, como han planteado Gómez y Harindranath (2020), a propósito de una etnografía del WhatsApp, se trata de "tecnologías vitales" que afectan prácticamente todas las dimensiones de la vida personal.

Las tecnologías nos han permitido mantener en movimiento actividades públicas desde los espacios y dispositivos

21. De acuerdo con la revisión de Serrano Puche (2016), podemos afirmar que las tecnologías son mediadoras de la expresión, la experiencia y la comunicación de sentimientos $\mathrm{y}$ emociones. 
privados. El hogar fue invadido de múltiples responsabilidades que se realizaban habitualmente fuera de él; los horarios de estas actividades se trastocaron, y la vida íntima enfrentó nuevos retos de conciliación, entre el trabajo remunerado en casa y el doméstico, los horarios de oficina/trabajo y los de descanso, los usos de los espacios del hogar (convertidos en oficinas, talleres o salones de clases), así como la priorización de actividades entre los miembros de la familia. ${ }^{22}$

La separación de la vida por espacios y horarios dejó de funcionar, fusionando lo público y lo privado, el trabajo y el ocio, las relaciones laborales con las familiares, en el marco de una intimidad doméstica de tiempo completo. Las tecnologías han sido reconocidas por lograr la presencia en la ausencia. Han sido el instrumento para estar en contacto con los familiares y amigos que no es posible visitar. Pero también, durante la pandemia, estas tecnologías han permitido la ausencia en la presencia, han hecho posible distanciarse de las relaciones inmediatas para recuperar espacios de privacidad o de mayor libertad para mantener otros vínculos laborales, familiares, de amistad o afectivos y sexuales.

\section{Las tecnologías y la socialidad afectiva}

Las diversas plataformas de Internet y los dispositivos móviles han potenciado la socialidad digital dentro y fuera de la pareja. Con los medios digitales las posibilidades de las personas para relacionarse, comunicarse y expresar sus afectos se han ampliado. En el ámbito de las parejas hemos observado que tienen repercusiones en el bienestar de cada uno, la expresión amorosa, pero también la vigilancia, los

22. La encuesta sobre habitabilidad documentó la convergencia de actividades laborales, domésticas y de entretenimiento en las viviendas: las tres actividades realizadas en la vivienda desde que rige el "Quédate en casa" más seleccionadas fueron: tareas domésticas $(\mathbf{9 0 . 8 \% )}$, ver contenidos en Netflix, Amazon, Claro (73.9\%) y trabajar en línea (74.9\%) (Ziccardi et al., 2020, gráfica 25). 
celos, la emergencia de "normas" para regular el uso de tecnologías propia y del otro, la gestión y el descubrimiento de secretos, y las expectativas de transparencia y privacidad (Rodríguez, 2019). La comunicación electrónica en la pareja es diversa, involucra dispositivos y plataformas especializadas, y abarca prácticas distintas según si viven juntos o llevan su relación a distancia. A través de ella se puede mantener el contacto virtual, pero también crear distancia artificial, así como organizar el día, expresar afectos, deseos, confesiones, o incluso simular la cohabitación cuando se trata de parejas a distancia (Cantó-Milà, Nuñez y Seebach, 2014).

Fuera de un contexto de pandemia, se ha reconocido que las tecnologías son impulsoras de confianza, apego y bienestar psicológico, en tanto permiten estar en contacto, sentirse acompañado aun en la distancia, permiten transmitir información y expresar afectos simultáneamente, y crean un sentido de cercanía e intimidad permanente, aunque también son objeto de molestias y discusiones. Estos efectos positivos de las tecnologías digitales en las relaciones de pareja, probablemente, en el contexto actual de confinamiento y de preocupación por la muerte a causa de un virus que se contagia fácilmente, ahora se han expandido a otras relaciones cercanas o íntimas, como las familiares y los amigos. Cabe destacar que también estos medios digitales tienen el potencial de impulsar relaciones con desconocidos, sin importar la distancia, gracias a su potencial desinhibidor, seductor, adictivo, y sus cualidades para la comunicación discreta y privada a través de dispositivos propios.

\section{Las parejas a distancia}

La necesidad impuesta por la pandemia de mantener relaciones personales a la distancia ha corroborado el 
enorme potencial que tienen las tecnologías para la intimidad y la expresión emocional, pero al mismo tiempo han mostrado sus grandes limitaciones para suplir la ausencia de la corporalidad y el consecuente roce de los cuerpos propios de las relaciones íntimas.

Las personas que viven en casas separadas, sea porque son novios o por sus propios arreglos de convivencia, durante la pandemia han funcionado, en alguna medida y temporalmente, como relaciones a distancia. En la encuesta virtual realizada, observamos que los encuestados que tienen parejas sin corresidencia fueron los más afectados en términos de la satisfacción con su relación de pareja. La pandemia, como observamos en las gráficas 8,9 y 5 , respectivamente, estuvo asociada con más frecuencia a cambios negativos (percepción de empeorar) en la satisfacción de la pareja, el bienestar personal y, sobre todo, la vida sexual entre quienes tienen parejas sin corresidencia. Con estos resultados, podemos inferir que la relación y la comunicación a través de medios digitales no han sido suficientes para paliar la desazón afectiva y sexual de las parejas que no han podido reunirse a causa de la cuarentena. Es importante destacar que dentro de este grupo se encuentran los jóvenes en relaciones de noviazgo, lo cual ha generado situaciones de grave afectación para su bienestar, puesto que, al vivir con sus padres o con personas vulnerables, no pueden ver a sus parejas para no poner en riesgo al resto de los miembros de sus familias.

Asimismo estos datos pueden interpretarse con algunos hallazgos más o menos establecidos sobre lo que significa llevar una relación a distancia. Según Stafford (2010), la separación geográfica durante el cortejo se acompaña de una comunicación que acentúa el afecto positivo y minimiza las diferencias, pero supone menores interdependencias y mayor incertidumbre sobre el futuro de la relación. Por su parte, Jiang y Hankcok (2013) muestran que las parejas a 
distancia se involucran en comportamientos más adaptativos para la revelación del sí mismo (para expresar pensamientos, experiencias y emociones propias), y tienden a mantener percepciones idealizadas de la pareja, dependiendo de la multiplicidad, la sincronía y la movilidad de los medios de comunicación empleados. Probablemente, esta variable comunicacional (tipos de medios y usos de ellos para mantener el vínculo) también esté afectando la adaptación de las parejas que temporalmente han estado separadas geográficamente por el confinamiento y conectadas solo a través de medios digitales.

Los retos identificados para las relaciones a distancia tenderán a ser los mismos que están viviendo las parejas que temporalmente no pueden verse ni tocarse a causa de la pandemia. La disminución del grado de satisfacción en estas parejas separadas geográficamente puede deberse a que mantienen el ideal establecido de la relación de pareja cercana físicamente (expresado en la sabiduría popular con el dicho "amor de lejos, amor de pendejos"), a las incertidumbres relacionales que crea la distancia y a que no han logrado adaptarse a formas de intimidad mediadas por las tecnologías; como, por ejemplo, a la intimidad emocional que se logra al compartir experiencias, pensamientos y sentimientos por medios digitales — a través de la escritura, la voz o la imagen - o a la intimidad sexual que supondría adquirir, a corto plazo, gusto y habilidades para el cibersexo o el sexting. ${ }^{23}$

23. Sexting hace referencia a las prácticas de crear, enviar, o recibir textos, imágenes o videos sexualmente sugestivos, como desnudos o semidesnudos, usando teléfonos celulares, aunque también puede ocurrir a través de computadoras y otros dispositivos electrónicos. El sexting puede ser parte de una actividad sexual regular, la extensión de una relación sexual existente, o un sustituto del encuentro cara a cara por jóvenes sexualmente inexpertos (Lenhart, 2009).

\section{2}




\section{Relaciones extraconyugales}

Otro tipo de relaciones de pareja que ha sido afectado por la pandemia, son las relaciones paralelas o extraconyugales. En nuestro contexto, tener relaciones extraconyugales o paralelas no tiende a ser aceptado moralmente, pero, al mismo tiempo, es un hecho que hombres y mujeres se involucran cada vez más en este tipo de relaciones, y que forma parte de la vida amorosa y sexual contemporánea, aunque se sigue considerando necesario mantenerlo en privado, pues constituye una amenaza a la pervivencia de la relación principal o matrimonial, declarada como monogámica. Probablemente porque esta forma de relación llama a la secrecía, la gran mayoría, el 90.3\%, de los encuestados, declara no tener una relación extraconyugal, mientras que el 9.7\% declara que sí la tiene. Nuestros datos no reflejan diferencias significativas por sexo, grupos de edad, ni años de relación. Las parejas que no residen juntas registraron una frecuencia mayor para tener una relación paralela o extraconyugal, frente a las que corresiden (14.4\% y $8.1 \%$, respectivamente).

La pandemia y el confinamiento causaron que este tipo de relaciones se vivieran, por una parte de los encuestados, como infidelidad en línea (online). Las tecnologías afectivas (Lasén, 2009) permitieron que aproximadamente cuatro de cada diez personas que declararon tener una relación extraconyugal o paralela mantuvieran dicho vínculo a pesar del encierro y la distancia con tecnologías de uso personal, aun dentro del propio hogar, probablemente en secreto y a través de la privacidad de los dispositivos móviles. Sin embargo, aproximadamente tres de cada diez de los respondiente, suspendieron la relación temporalmente y los tres restantes mantuvieron la relación igual. Las variables de grupos de edad, sexo y años de relación no observaron diferencias significativas. Dentro del subconjunto de encuestados que 
respondieron tener una relación paralela $(n=74)$, la mayor parte continuó este tipo de relación a través de tecnologías de comunicación (43.2\%), seguidos por quienes optaron por suspenderla (29.7\%) y quienes la mantuvieron igual (27\%). En este aspecto, los encuestados que corresiden con sus parejas primarias fueron quienes registraron frecuencias más altas para suspender la relación paralela (35.6\%), con respecto a parejas sin residencia común (29.7\%), así como quienes registraron una menor frecuencia para mantener la relación a través de las tecnologías de comunicación (31.1\%), con relación a quienes viven separados de sus parejas primarias (62.1\%). Curiosamente, la opción de mantener la relación igual fue registrada más por encuestados con residencia común con su pareja primaria (33.3\%) que por quienes no residen con ella (17.2\%). El factor de compartir la residencia con el esposo, la esposa o la relación primaria genera diferencias en el tener o no una relación extraconyugal y la forma en que esta última fue afectada por la pandemia. Estos datos muestran que los retos para mantener este tipo de relaciones paralelas son más fuertes para quienes están cohabitando durante el confinamiento. Parecería que la cohabitación ha obligado a suspender la relación y limitado su continuación a través de medios digitales, aunque en algunos casos ha sido posible mantenerla igual.

Respecto de este asunto dentro de nuestra encuesta, se dio un espacio de respuesta de tipo abierto para describir la forma como se ha afectado la relación extraconyugal durante el confinamiento. Las respuestas vertidas allí revelan experiencias diversas para estas personas, en su gran mayoría negativas; ahí expresaron: extrañamiento, necesidad del otro, disminución o total ausencia de vida sexual, distanciamiento o alejamiento, baja en el nivel de comunicación, desmotivación, estrés, agotamiento, ansiedad e incertidumbre, rabia frente al cierre de moteles y conflictos por celos. Algunas de las respuestas también mencionan 
la disminución del deseo sexual y la desaparición de un espacio de privacidad por la presencia en casa de la esposa o el esposo, aunque puedan comunicarse virtualmente. ${ }^{24}$ Esta experiencia ha sido extremadamente significativa en muchos casos, al grado de afirmar que lo peor de la pandemia ha sido tener que dejar de ver a sus amantes. En estas respuestas también se revela que las salidas indispensables, como salir a hacer las compras, fueron los momentos que se aprovecharon para encontrarse con la relación paralela.

\section{Usos sexuales de la Internet}

Las tecnologías asociadas a Internet han abierto oportunidades para la gestión de encuentros sexuales con desconocidos (aplicaciones de citas y redes sociales principalmente), o para interactuar sexualmente cuando las parejas están separadas geográficamente (por ejemplo, a través de chats eróticos o videollamadas sexuales). Internet, durante el periodo de la pandemia, ha sido un medio para mantener intimidad sexual a pesar de la distancia. En una pregunta sobre la experiencia de usos más frecuentes de Internet en el que se plantearon catorce respuestas predefinidas, se incorporaron dos respuestas sobre usos sexuales que registraron un porcentaje de selección baja entre los encuestados. Solo el 9.9\% de los respondientes seleccionó ver pornografía en Internet, mientras solo el $2.5 \%$ eligió tener cibersexo. Estos datos nos permiten afirmar que los usos sexuales de Internet no fueron casi elegidos por la muestra estudiada (en este caso, compitiendo con otras clases de usos más comunes o menos estigmatizados). No obstante, es interesante observar las diferencias por sexo. En el caso de los hombres, el $23.7 \%$ seleccionó ver pornografía en Internet, frente al $4.4 \%$ de las mujeres. También los jóvenes seleccionaron

24. También hubo respuestas que indicaron que no les afectaba y que seguían en interacción, aunque no presencial, estas fueron la minoría. 
esta respuesta con mayor frecuencia (14.3) con respecto a los otros grupos de edad (6.5 en adultos medios y 7.5 en adultos mayores). Curiosamente, en lo que corresponde a tener cibersexo, esta respuesta fue seleccionada ligeramente más por mujeres $(2.8 \%)$ que por hombres $(1.9 \%)$, pero no es un resultado definitivo.

Una experiencia de cómo son usados el sexting y las videollamadas sexuales, así como el significado que revisten, es narrada por una joven de la ciudad de México, quien antes de la pandemia conoció a un chico al cual dejó de ver cuando comenzó el confinamiento, y redujo su relación al intercambio de mensajes,

Conforme fueron pasando los días comencé a sentir soledad. Me llevaba bien con él, me gustaba mucho, puedo decir que me enamoré. Al principio nos enviábamos fotos de las cosas que nos gustaban en nuestras casas. Después le dije que me mandara una de la parte de su cuerpo que más le gustara. Recibí una imagen de su mano y yo correspondí con una de mi clavícula. Pero un día me desperté súper horney y le mandé un mensaje diciéndole: 'Oye, estoy un poco cachonda'. Y decidimos hacer una videollamada.A la tercera le dije que si quería verme desnuda. "Generalmente no hago este tipo de cosas, pero también me atreví porque necesitaba sentirme deseada, sentía ganas de que alguien me viera, de gustarle y que me quisiera. Tener algún tipo de contacto, aunque evidentemente no es físico, pero sí erótico. No fue una onda de enfocar nuestros genitales, más bien de compartir un deseo mutuo de cariño. La experiencia fue muy enriquecedora porque el aislamiento que hoy vivimos no solo es físico, también es emocional. Y tener este contacto cubrió ciertas necesidades emocionales y psicológicas que yo tenía de amor y de deseo", refiere la profesional (La Jornada, I de junio, 2020).

Otro aspecto relativo al uso sexual de la Internet es el de las aplicaciones móviles de citas o de búsqueda de relaciones sexuales, las cuales diversas publicaciones han indicado que 
Intimidad y relaciones de pareja durante la pandemia de la CovID-19 en Guadalajara

tuvieron un notable repunte, tal es el caso de la plataforma Gleeden:25

Gleeden ha registrado un incremento en las conexiones de los usuarios de hasta $160 \%$, es decir que el sitio ha registrado más visitas durante el periodo de cuarentena y es en estos días que ha registrado la mayor cantidad de estas que en toda la historia del sitio, que fue en 2009. Los más de 6 millones de usuarios del sitio han registrado una conexión de al menos una vez durante el periodo de cuarentena.Además, el sitio ha registrado un promedio de 50\% más de tiempo de conexión (Infobae, mayo, 2020).

Una aplicación especialmente popular en México es Tinder, ${ }^{26}$ la cual cuenta con más de 50 millones de usuarios en el mundo; es gratuita, aunque ofrece algunos servicios adicionales cuando el interesado paga por ellos. A través de esta aplicación las personas inscritas encuentran coincidencias entre perfiles y hacen match cuando ambos se interesan mutuamente. Sean casados o solteros, los usuarios de Tinder han usado la aplicación en medio del confinamiento. Esto ha sido más frecuente entre quienes están solos y no tienen hijos, pues el riesgo que implica tener contacto con extraños se asume de mejor forma si no ponen en riesgo a otras personas. En el caso de quienes aun corriendo riesgos se lanzan a tener encuentros sexuales, es común que ocurra una especie de debate moral entre la culpa generada por romper el confinamiento que se contrapone a la ganancia de haber tenido una relación placentera y satisfactoria. ${ }^{27}$

25. La plataforma de Gleeden se define como "el ler sitio de encuentros extraconyugales pensado por mujeres" con 6,987,663 miembros en todo el mundo. Disponible en: https://es.gleeden.com/.

26. Para mayor información sobre esta aplicación: https://es.wikipedia.org/wiki/ Tinder.

27. Relatos de este tipo de experiencias se encuentran en el artículo "La seducción, el amor y el sexo en medio del coronavirus". La Jornada, I de junio de 2020. 


\section{Las interferencias de las tecnologías}

en la convivencia en pareja

Durante el confinamiento, los espacios del hogar obligaron a una convivencia íntima doméstica de tiempo completo y las tecnologías fueron, por desgracia o por fortuna, una de las maneras de aislarse del entorno inmediato y vincularse con otros y otras, a través de dispositivos privados y móviles. Los usos privados, individualizados, de Internet ocurren principalmente a través de la comunicación móvil y refuerzan estilos de relación de pareja en los que las actividades de ambos se realizan por separado y no de manera conjunta. En este sentido se puede afirmar que se trata de tecnologías que fortalecen y legitiman roles individualizados y susceptibles de afectar la interacción o la convivencia en pareja. MacDaniel y Coyne (2016, p. 85) introducen el concepto de "tecnoferencia" para referir "las intrusiones cotidianas o interrupciones en las interacciones de pareja o en el tiempo que pasan juntas que ocurre a causa de tecnología”. Este tipo de interferencias afecta las relaciones de pareja de dos maneras: en primer lugar, las personas pueden desarrollar “....intimidad' con sus dispositivos electrónicos a costa de la intimidad de la vida real” (por el apego emocional que implican). Y, en segundo lugar, porque "las personas pueden realizar... 'multitareas' con la tecnología mientras interactúan con otros". Estas interferencias son importantes porque conllevan la experiencia de "estar solos juntos", representan situaciones o momentos de multitareas mediadas y pueden afectar negativamente las interacciones de pareja y la relación misma. Cabe señalar que estas intrusiones pueden ser causadas por los dispositivos, como cuando se reciben llamadas, textos o notificaciones, y no necesariamente por un comportamiento problemático de las personas con la tecnología (MacDaniel y Coyne, 2016).

\section{8}


En un contexto de encierro y de intimidad doméstica de tiempo completo, la tecnoferencia puede significar tanto un elemento disruptivo de la convivencia en pareja como un respiro para enfrentar la pesadez de una situación de confinamiento y de restricción de la socialidad fuera del ámbito de la pareja y la familia. En el periodo de quedarse en casa, los usos de tecnologías se expandieron al ámbito laboral y de estudio, al mismo tiempo en que se acentuaron los usos para información, comunicación y entretenimiento. Este incremento extraordinario en el uso de tecnologías hizo emerger un escenario familiar más proclive a las interrupciones o intromisiones en las interacciones de pareja a partir de dispositivos tecnológicos. En la encuesta virtual realizada exploramos las percepciones de los respondientes sobre las posibles interferencias en la convivencia de pareja de los siguientes dispositivos de comunicación o entretenimiento: el teléfono celular, las series televisivas y los videojuegos. Como podrá observarse enseguida, de estos tres dispositivos, el que registra niveles más altos de frecuencias de interferencias con las interacciones de pareja es el teléfono celular.

El 51.4\% de los respondientes declaró con una frecuencia media/baja (ocasionalmente o algunas veces en la semana) que el teléfono celular ha interferido en la convivencia en pareja durante el confinamiento, mientras que el 11.6\% señaló una frecuencia alta/constante (casi diario o diario). En conjunto, seis de cada diez de los encuestados refirió algún nivel de frecuencia para interferencias a causa del teléfono celular. Esta frecuencia, obviamente, es más alta para los encuestados que corresiden con su pareja que para los que viven en casas distintas $(55.4 \%$ y $40.6 \%$ con una frecuencia media/baja y $13.1 \%$ y $7.4 \%$ con frecuencia alta/ constante respectivamente) (gráfica 10). Los teléfonos móviles tienen este potencial para interferir en las relaciones de pareja y, en realidad, en cualquier otro tipo de relación, por el apego que generan en sus usuarios, por la compulsión a 
ver notificaciones de mensajes recibidos y por la posibilidad de mantener, de manera relativamente privada, comunicación con otros vínculos afectivos. Se trata de un dispositivo que tanto permite la presencia en la ausencia, como la ausencia en la presencia. La ausencia en la presencia con el uso del celular es causa de molestias en la pareja. Este resultado se refuerza con otro proveniente de una pregunta general sobre las tensiones o conflictos de pareja durante la pandemia, que incorporó la opción de respuesta "Mi pareja pasa mucho tiempo en su celular" entre un conjunto de quince respuestas predefinidas de diversa índole. Los encuestados seleccionaron esta opción como la segunda más importante para crear tensiones y conflictos (29.7\%). Esta opción quedó solo debajo de la respuesta más elegida que, fue estrés por el encierro durante la pandemia de la Covid-19 y superó a otros motivos, como la falta de temas de interés comunes, la no colaboración en los quehaceres domésticos, el trabajar en casa y convivir con la familia al mismo tiempo, el cuidado de los hijos, las adicciones, la violencia o la salud, entre otros. Adicionalmente, la opción que quedó en el séptimo de lugar de respuestas más elegidas fue la tensión causada por el tiempo que su pareja pasa en actividades en Internet (redes sociales, chats, etcétera) (gráfica 3). 


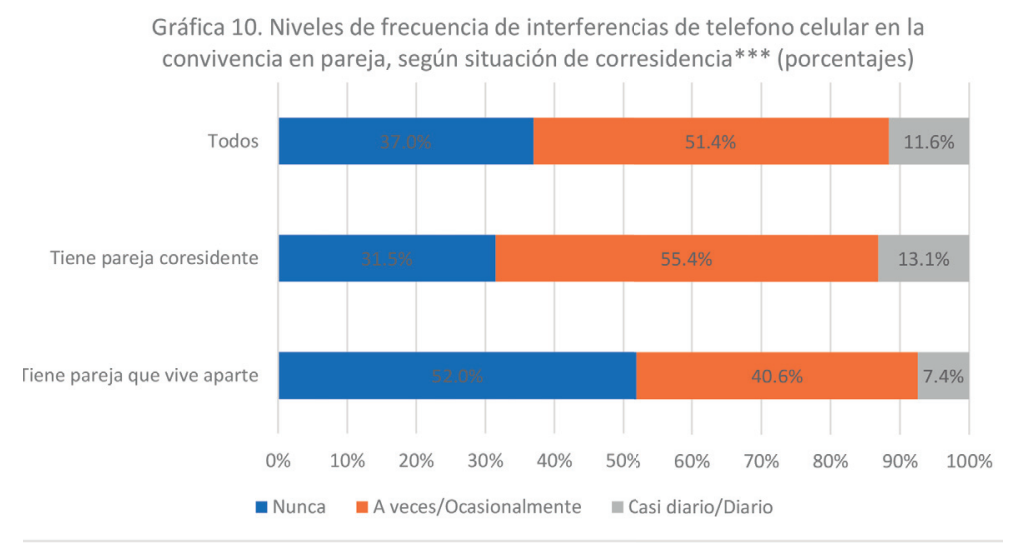

En lo concerniente a las series televisivas, del conjunto de los encuestados, el 29.5\% indicó una frecuencia media/baja y el $3.4 \%$ una frecuencia alta/constante, mientras que el $67.1 \%$ declaró que nunca le ha ocurrido. Cabe señalar que el tiempo de estar juntos en pareja hace una diferencia: el $74.9 \%$ de quienes tienen parejas con menos de diez años juntos respondió nunca haber vivido esta interferencia, frente al $60.1 \%$ de quienes tienen parejas de más de diez años (gráfica 11). Es probable que esto se deba a que las parejas más jóvenes realicen el visionado de series de manera conjunta, mientras que en las parejas de mayor tiempo el consumo de estos productos sea más individualizado. 


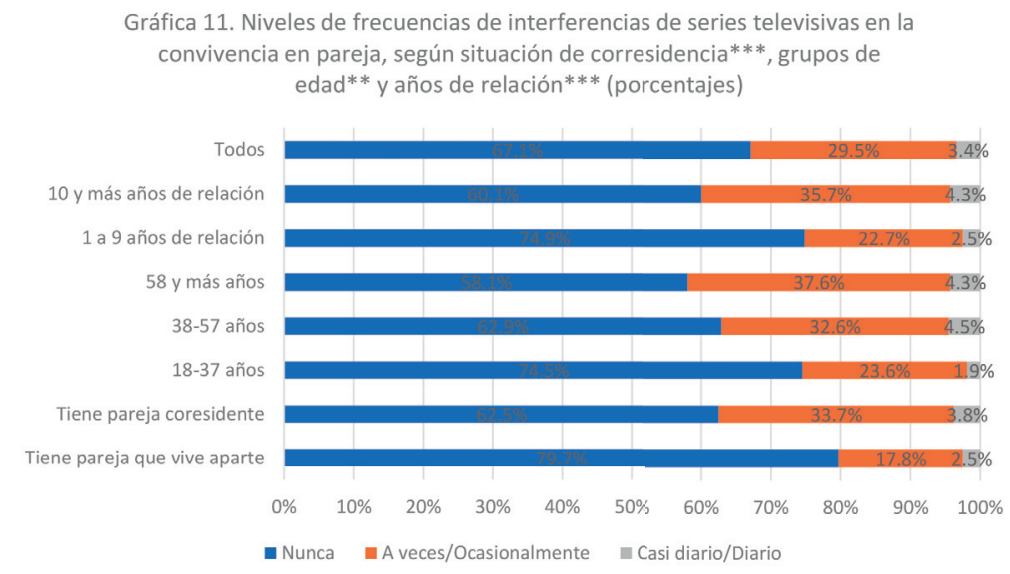

Finalmente, los videojuegos fueron dispositivos que no obtuvieron niveles de frecuencia importantes en cuanto a interferir en la convivencia de pareja: el $82.8 \%$ de la muestra estudiada señaló que nunca le ha ocurrido.

\section{Las actividades de Internet, acuerdos y desacuerdos}

Las actividades en Internet de los miembros de la pareja son objeto de negociaciones y regulaciones en la vida cotidiana. Durante la intimidad doméstica de tiempo completo que ha implicado la pandemia, estos arreglos podrían haber cobrado relevancia, toda vez que Internet se convirtió en pieza clave para llevar a cabo múltiples actividades públicas. Como se ha observado en otros estudios, se suele discutir y llegar a acuerdos, o no, sobre el tiempo que cada uno pasa en Internet, el tipo de actividades que son consideradas correctas, así como con quiénes se está interactuando. En la encuesta virtual observamos que solo el $24.5 \%$ declara haber discutido con su pareja sobre sus actividades en redes sociales o Internet durante la pandemia. Este dato indica que no se trata de una experiencia generalizada en la muestra obtenida. No se observaron diferencias significativas por 
sexo, pero sí por los años de relación de pareja. Las parejas de menos de diez años respondieron con más frecuencia que sí han discutido (29\%), en contraste con las de diez años y más de relación (20.4\%), que también contestaron afirmativamente. Esto puede interpretarse en el sentido de que los adultos jóvenes están siendo más afectados por los usos de Internet propios y de sus parejas, probablemente, agudizados por el confinamiento (gráfica 12).

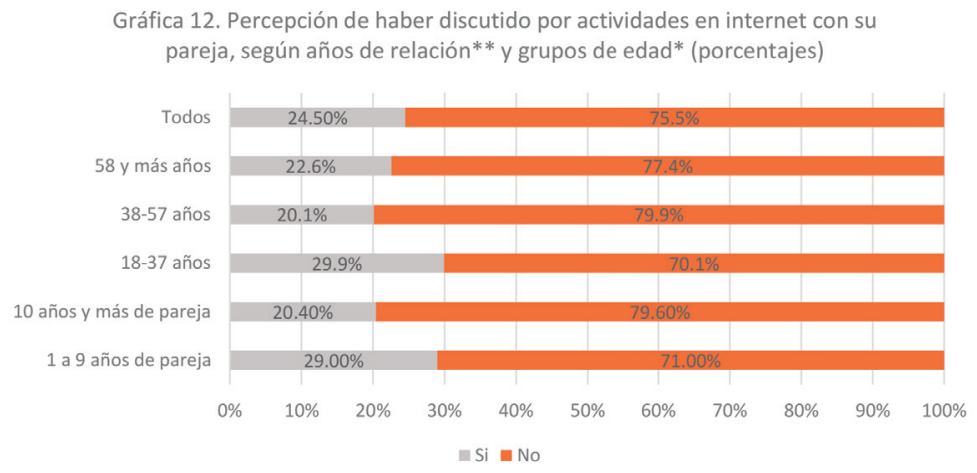

La experiencia de sentir celos por contactos en redes sociales e Internet la informaron dos de cada diez respondientes. Su presencia es más intensa en las parejas sin residencia conjunta y en los más jóvenes. En este sentido, cuatro de cada diez de los que tienen parejas que viven en casas distintas informan algún nivel de frecuencia, frente a solo dos de cada diez entre quienes corresiden. Las incertidumbres que genera la distancia física, la falta de copresencia y, probablemente, de un vínculo formalizado, parecerían ser aspectos importantes para sentir celos en Internet. También la edad de los informantes es importante. En el grupo de jóvenes (18-37 años), aproximadamente tres de cada diez registraron algún nivel de frecuencia para sentir celos por contactos en Internet, mientras que en los 
otros grupos de edad (38-57 años y 58 años y más) decrece aproximadamente a dos de cada diez (gráfica 13).

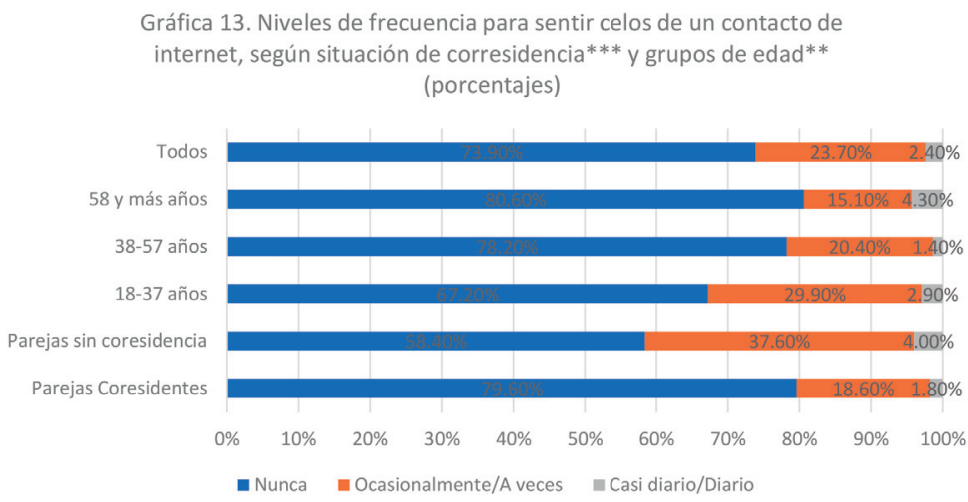

Los dispositivos móviles para la comunicación con otros, privados y discretos, se han vuelto instrumentos claves para la conversación emocional y erótica con la pareja y con vínculos más allá de la relación primaria. El teléfono celular tiene la cualidad de almacenar registros de las interacciones con otros, desde mensajes o chats privados hasta llamadas, fotos, entre otras inscripciones digitales. Cualitativamente, se ha observado que para las parejas es una tentación acceder al dispositivo del otro o la otra en aras de reducir incertidumbres o adquirir certezas de que no hay una relación en ciernes o establecida fuera de la relación en la que uno se encuentra. No obstante, se trata de un comportamiento intrusivo, éticamente condenable, pero muy tentador cuando se tienen dudas o celos. Revisar el celular de la pareja sin que ella se entere durante el confinamiento fue registrado solo por uno de cada diez de los respondientes, y se observa un énfasis mayor en el caso de las mujeres (gráfica 14). Esto podría indicar que la situación de confinamiento, las restricciones al movimiento y a las actividades fuera de casa son un elemento estabilizador de 
la confianza en la pareja o de reducción de incertidumbres relacionales.

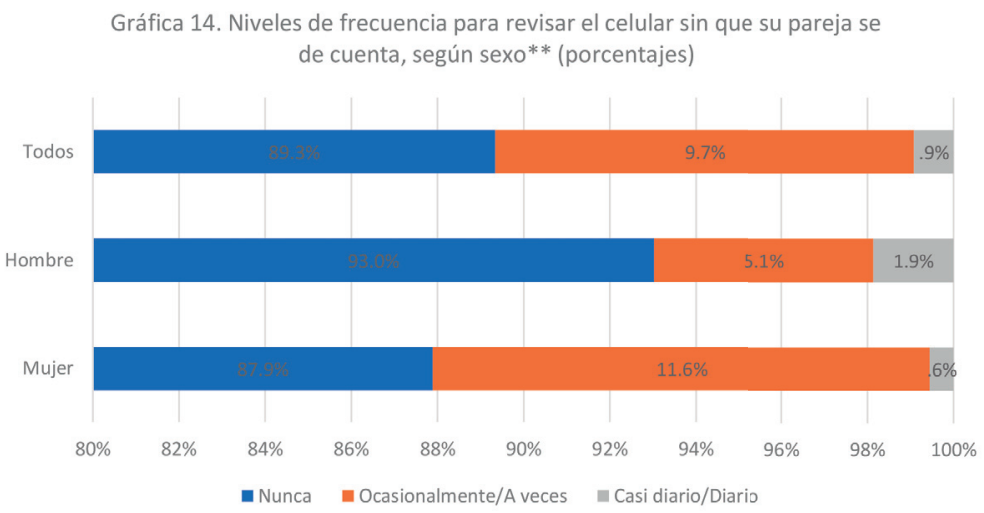

Las principales diferencias de pareja en torno a los usos de Internet son sobre el tiempo que el respondiente o la pareja le dedican. Recordemos que el tiempo que implica el uso de las tecnologías puede minar la calidad o cantidad de la convivencia, y en este sentido puede ser motivo de tensiones, conflictos o desacuerdos con la pareja. Del conjunto de respondientes $(n=186)$ que declararon discutir con su pareja por usos de Internet durante el "quédate en casa", el 50.5\% incluyó entre sus menciones desacuerdos por el tiempo que su pareja le dedica a actividades en Internet, seguido por el $43 \%$ que incluyó la opción de desacuerdos por el tiempo que usted le dedica a actividades en Internet. Este resultado converge con que el dispositivo que más interfiere en la relación de pareja es el teléfono celular, y muestra que entre la pareja hay molestias o discusiones en torno a los usos que hace el otro o la otra. Las siguientes opciones más elegidas por los encuestados, aunque en proporciones menores, tienen que ver con la regulación del comportamiento en los usos de Internet cuando se está en pareja: el $28 \%$ seleccionó por diferencias en torno a qué es 
o no correcto hacer en redes sociales o Internet, seguido por el 17.7\%, que eligió celos por la forma en que su pareja interactúa con algún contacto de Internet, y el 16.1\%, que indicó sospechas de infidelidad o pérdida de confianza, entre otras opciones con porcentajes menores (gráfica 15).

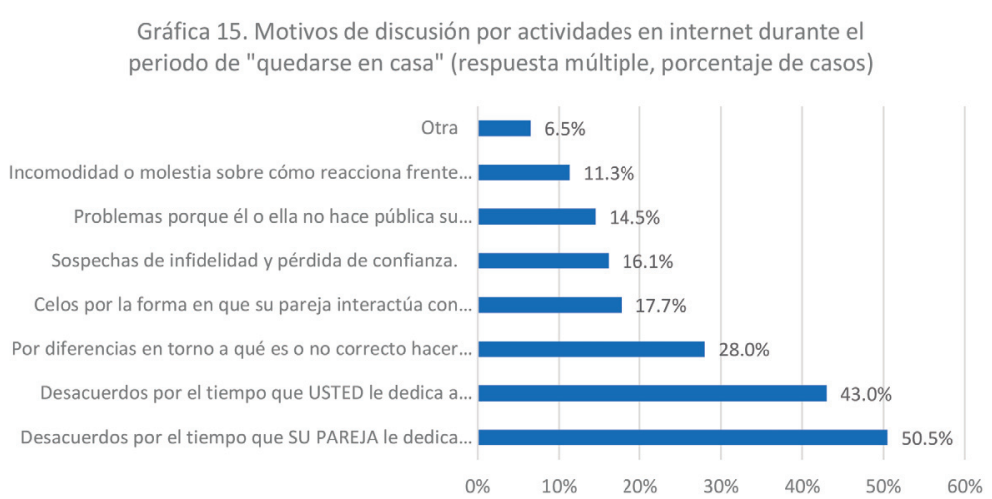

En este sentido, puede afirmarse, que aun en el encierro, las actividades en Internet son objeto de discusiones en la pareja, en primer término, porque interfieren en la convivencia, y, en segundo lugar, porque hay desacuerdos sobre lo que es aceptable hacer o no hacer en Internet, celos y sospechas de infidelidad. La comunicación por Internet parece ser reconocida por una gran parte de los respondientes como algo que potencia el bienestar de la pareja y del yo, pero que, a su vez, acarrea riesgos potenciales, como las interferencias tecnológicas en las relaciones de copresencia.

\section{Conclusiones}

Dos meses han pasado luego de haberse levantado la encuesta virtual de la cual resultaron los datos expuestos en este trabajo. Es probable que las experiencias en la vida íntima de las parejas descritas anteriormente se hayan 
profundizado, y vueltos más drásticos sus efectos negativos, debido al cansancio del encierro y la incertidumbre sobre el futuro. La pandemia sigue sin control en el mundo, mientras que, en nuestro país, aún no se estaciona su crecimiento. El período de confinamiento permanece y no se tiene claridad sobre la fecha de su finalización, lo cual agudizará las afectaciones en las relaciones de pareja y la vida familiar. Muy posiblemente veremos la emergencia de nuevos fenómenos, tales como el hartazgo ante las videollamadas, que se han vuelto rutinarias, que han perdido su novedad y que ya no logran mantener la atención de los participantes. Probablemente, las citas en línea, las experiencias de sexting y de cibersexo adquieran mayor popularidad, ante un periodo indefinido de cuándo regresar a la "normalidad".

Como vimos en las páginas anteriores, la socialidad afectiva se transformó en el contexto de la pandemia. Se ha volcado a los escenarios virtuales en los que se replican usos de tecnologías que ya estaban incorporados en las rutinas diarias y, a la vez, se incorporan nuevos usos y plataformas antes desconocidas. Esto ha implicado procesos de alfabetización digital intensos, incentivados por las necesidades de trabajo, entretenimiento, de relación con familiares, amigos, o parejas que no viven en la misma casa. En este escenario, la gran mayoría de las personas conectadas ha conocido más el potencial de las tecnologías para mantener relaciones íntimas a distancia y expresar afectos a través de medios digitales, aunque en la muestra estudiada (urbana y de alta escolaridad) los usos sexuales están lejos de haber sido incorporados en las interacciones de pareja.

Como también expusimos en el artículo, los jóvenes son el grupo etario más afectado por el confinamiento, en particular en su vida sexual. Es común que en los primeros años de unión o matrimonio el ámbito de la sexualidad tenga una mayor relevancia y las parejas tengan prácticas sexuales más recurrentes por el hecho de encontrarse en 
una fase de enamoramiento donde el deseo sexual es más intenso (Alberoni, 1987; Fisher, 2004), en contraste con etapas posteriores de la relación de pareja. En ese sentido, el confinamiento ha empobrecido las condiciones materiales para que se den tales prácticas, por la pérdida de espacios de privacidad para las parejas y el tener tiempo completo los hijos en casa; mientras que otras condiciones de tipo emocional, tales como la pérdida de espacios de enriquecimiento venidos de la socialidad presencial en los ámbitos laboral y amistoso, el cansancio venido de la convivencia de veinticuatro horas los siete día de la semana de las parejas entre sí, así como un contexto mediático catastrófico y desesperanzador, también han contribuido a su deserotización.

En el caso de los jóvenes que no son corresidentes, pero están en situaciones de noviazgo, así como las personas que tienen relaciones extraconyugales, el confinamiento los ha colocado en una situación de debate moral en el que su propio bienestar y satisfacción se opone a la lógica de cuidados y disminución de riesgo que se obligan a tener, no solo por el bienestar propio, sino también por el riesgo que correría el resto de miembros de sus familias (adultos mayores y personas vulnerables), o sus parejas formales.

Otro hallazgo que nos parece fundamental es la poca relevancia que muestran los datos respecto de las diferencias por sexo en las preguntas trabajadas. Los únicos temas en que aparecieron distinciones genéricas relevantes fueron que las mujeres extrañan más la privacidad y el no estar solas con sus parejas en el confinamiento, un menor uso de pornografía en Internet y una mayor frecuencia en la experimentación de conflictos y tensiones. Por su parte, los varones tienen más energía y exploran prácticas sexuales novedosas. Es probable que, como señalan estudios cualitativos al respecto (Tenorio, 2012), grupos sociales urbanos, de clases medias y medias altas, con formación educativa superior (como la muestra que respondió nuestra encuesta), 
están desarrollando relaciones de pareja más equitativas y menos desiguales genéricamente, aunque, como vemos, persisten algunas diferencias.

Por otra parte, el que el grado de satisfacción con las parejas en general no decrezca durante el confinamiento posiblemente apunta en el sentido de que las relaciones íntimas se nutren de varios componentes, como los que señala Robert Sternberg en su perspectiva triangular sobre las relaciones amorosas. Para este autor, las relaciones involucran deseo sexual, compromiso y propiamente intimidad, la cual es entendida como el conjunto de vínculos e interconexiones entre los miembros de la pareja que se traducen en potenciar el bienestar de cada uno, sentirse feliz en su compañía, concederse mutuamente consideración, valoración y comprensión, la voluntad de dar y recibir apoyo emocional y comunicarse profundamente (Sternberg, 2000, pp. 19-20). En este sentido, la experiencia del confinamiento adquiere tintes positivos cuando justamente la intimidad se profundiza e intensifica, y por eso no extraña que las parejas de adultos mayores, y de quienes poseen mayor número de años de vida en común, registren índices más altos de mejoría en su relación durante el encierro, período en el que sentimientos de vulnerabilidad, miedo y riesgo están presentes cotidianamente y son positivamente compensados por sus parejas. Asimismo, cobra sentido que la principal razón para considerar separarse o divorciarse sea la falta de comunicación.

Asimismo, pero en sentido inverso, el distanciamiento físico al que se han visto sometidas las personas que no comparten la casa las ha hecho sufrir el confinamiento de maneras que ni la Internet, ni los dispositivos móviles, han podido compensar; como dice Rosa Montero (2020a), "Somos criaturas sociales. Necesitamos sentir la proximidad de nuestros iguales. El roce, la caricia, los abrazos (...) ¿Y cómo serán esos primeros abrazos? Simplemente grandiosos". 
Bibliografía

Alberoni, F. (1987). Enamoramiento y amor. México: Gedisa. AMSSAC (2020). Sexualidad y covid- 19. Resultados de la encuesta AMSSAC. Resumen ejecutivo de resultados. Disponible en: https://www.amssac.org/sexualidad-y- covID- | 9-resultados-de-la-encuesta-amssac/.

- (2020a). Cambios en la conducta sexual por el confinamiento de la pandemia covid-19. Resultados parciales. Disponible en: https://www.amssac.org/wp-content/uploads/2020/06/Cambios-en-la-conducta-sexual-por-el-confinamiento-de-la-pandemia- coviD- I9.pdf. (2020b). Panorama de la violencia reportada. Resultados parciales. Disponible en: https://www.amssac.org/ wp-content/uploads/2020/06/Panorama-de-la-violencia-reportada.pdf.

Blasius, J.y M. Brandt (20I0)."Representativeness in Online Surveys through Stratified Samples". Bulletin de Méthodologie Sociologique, 107, 5-2I, SAGE.

Cantó-Milà, N. ; Nuñez, F. y S. Seebach (20I4). "Send me a Message and l'll callYou Back:The Late ModernWebbing of Everyday Love Life”. En R. Benski y E. Fisher (Ed.). Internet and Emotions. Nueva York: Routledge, I44-I 58.

Chaumier, S. (2006). El nuevo arte de amar. Madrid: Alianza Editorial.

Consulta Mitofsky (2020)."Los mexicanos en la cuarentena", mayo. Disponible en:http://www.consulta.mx/index.php/ encuestas-e-investigaciones/item/I352-cuarentena-mxmay20.

Cruz, E. G., y, R. Harindranath (2020). "Whatsapp as 'Technology of Life': Reframing Research Agendas". First Monday, 25 (12). Disponible en: https://doi.org//0.5210/ fm.v25il 2. 10405 .

Díaz de Rada, V. (20I2). "Ventajas e inconvenientes de las encuestas por Internet”, Papers, 97/I, 193-223. Disponible en:

Fisher, H. (2004). ¿Por qué amamos? México:Taurus. 
Frippiat, D.; Marquis, N. y E. Wiles-Portier (2010). "Web Bibliografía

Surveys in the Social Sciences:An Overview”. Population, vol. 65, núm. 2, abril-junio, 285-3II.

Illouz, E. (2020). El coronavirus y la insoportable levedad del capitalismo. Nueva Sociedad. Disponible en: https://nuso. org/articulo/coronavirus-capitalismo-emociones-illouz/. Infobae (2020a). Cuarentena en pareja: la decisión que revela en qué estado se encuentra la relación, 23 de marzo. Disponible en: https://www.infobae.com/america/ tendencias-america/2020/03/23/cuarentena-en-pareja-la-decision-que-revela-en-que-estado-se-encuentra-la-relacion/.

(2020). Cuarentena de infieles: $68 \%$ de los mexicanos extrañan a sus amantes, 22 de mayo. Disponible en: https://www.infobae.com/america/mexico/2020/05/22/ cuarentena-de-infieles-68-de-los-mexicanos-extranan-a-sus-amantes/.

Instituto Federal de Comunicaciones, IFT (2019). “Apartado I. Patrones de consumo y experiencia en el uso de los servicios de telecomunicación". En Primera encuesta. Usuarios de servicios de telecomunicaciones. Instituto Federal de Comunicaciones, $x-x$ Disponible en: http:// www.ift.org.mx/sites/default/files/contenidogeneral/ usuarios-y-audiencias/primerencuesta20 I 9 vacc.pdf.

Instituto Nacional de Estadística, Geografía e Informática (2019). Encuesta Nacional sobre Disponibilidad y Uso de Tecnologías de la Información en los Hogares. EDUTIH. Disponible en: https://www.inegi.org.mx/programas/ dutih/2019/.

(2020). INEGI toma medidas extraordinarias por el estado de emergencia sanitaria originada por el Covid-19, 3 I de marzo. Disponible en: https://www.inegi.org.mx/ contenidos/saladeprensa/boletines/2020/especiales/ INEGI- COVID.pdf. 
Bibliografía
Israde, Y. (2020). Elogio del ocio y la lentitud. Disponible en: https://www.reforma.com/aplicacioneslibre/ preacceso/articulo/default.aspx?_rval=| \&urlredirect=https://www.reforma.com/elogio-del-ocio-y-lalentitud/ar I 955 I 83? referer=--7d6 I6 I 65662f3a3a6262623b727a7a7279703b767a783b786d3a--.

Marchis, G. de (2012).“'La validez externa de las encuestas en la web.Amenazas y su control”. Estudios sobre el Mensaje Periodístico, vol. I8. núm. especial, octubre, 263272, Disponible en: http://dx.doi.org/I0.5209/rev_ESMP.20I 2. vl8.40980.

Jiang, C. y J.T. Hancock (20I3). “Absence makes the Communication grow Fonder: Geographic Separation, Interpersonal Media, and Intimacy in Dating Relationships". Journal of Communication, 63 (3), 556-577. Disponible en: DOI: I 0.I I I I/jcom. 12029.

La Jornada (2020). La seducción, el amor y el sexo en medio del coronavirus, I de junio. Disponible en: https://www. jornada.com.mx/ultimas/sociedad/2020/06/0 I/la-seduccion-el-amor-y-el-sexo-en-medio-del-coronavirus-3162.html.

Lasén,A. (2009). “Tecnologías afectivas: de cómo los teléfonos móviles participan en la constitución de subjetividades e identidades". En G. Gatti, I. Martínez de Albéniz y B.Tejerina (Ed.). Tecnología, cultura experta e identidad del conocimiento. Bilbao: Universidad de País Vasco, 21 5-248. Lenhart, A. (2009) “'Teens and Sexting: How and why Minor Teens are sending Sexually Suggestive Nude or Nearly Nude Images Via Text Messaging”. Pew Research Centre Report. Disponible en: https://www.pewlnternet. org/2009/12/I5/teens-and-sexting/.

McDaniel B. T. y S. M. Coyne (20I6). "Technoference: The Interference of Technology in Couple Relationships and Implications for Women's Personal and Relational 
Well-being”. Psychol.Pop. Media Cult., 5,85-98. Disponible Bibliografía en: DoI: 10.1037/ppm0000065.

Montero, R. (2020).“El tiempo de la peste”, columna Maneras de vivir, El país, 28 de marzo. Disponible en:https://elpais. com/elpais/2020/03/24/eps/I585052807_09/060.html. - (2020a). “Simplemente grandiosos", columna Maneras de vivir, El país, I I de abril. Disponible en: https:// elpais.com/elpais/2020/04/06/eps/I586181769_958126. html.

Observatorio Ciudadano Jalisco Cómo Vamos (2020). Encuesta de percepción y experiencia de la población del Área Metropolitana de Guadalajara (AMG) en torno al covID19. Segunda encuesta telefónica, I 4 de mayo. Disponible en: http://jaliscocomovamos.org/2-amg-coviD- 19.

Ramonet, I. (2020). La pandemia y el sistema mundo. Disponible en: https://www.jornada.com.mx/ultimas/ mundo/2020/04/25/ante-lo-desconocido-la-pandemia-y-el-sistema-mundo-7878.html.

Rodríguez Morales, Z. y T. Rodríguez Salazar (Coord.) (20I3). Socialidades y afectos.Vida cotidiana, nuevas tecnologías y producciones mediáticas. México: Universidad de Guadalajara. Rodríguez, T. (20l7). El amor y la pareja. Nuevas rutas en las representaciones y prácticas juveniles. México: Universidad de Guadalajara.

(2019). “Internet en las relaciones de pareja establecidas: un panorama desde la investigación internacional”. En Ana Josefina Cuevas (Coord.). Intimidad y relaciones de pareja: exploraciones de un campo de investigación. Ciudad de México: Juan Pablo Editores, Universidad de Guadalajara, 293-329.

et al.(2019).“La intimidad en las relaciones de pareja: reflexiones conceptuales a partir de su multidimensionalidad”. En Ana J. Cuevas, (Coord.). Intimidad y relaciones de pareja: exploraciones de un campo de investigación, México: Universidad de Guadalajara/Juan Pablos Editores, 37-94. 
Bibliografía

Serrano-Puche, J. (20I6). "Internet y emociones: nuevas tendencias en un campo de investigación emergente”. Comunicar, 24 (46), 19-26.

Stafford, L. (2010)."Geographic Distance and Communication during Courtship”. Communication Research, 37, 275-297. Disponible en: DOI: I0.I I 77/0093650209356390.

Sternberg, R. (2000). La experiencia del amor, España: Paidós. Tenorio, Natalia (20I2). "Repensando el amor y la sexualidad: una mirada desde la segunda modernidad”. Revista Sociológica, 27 (76), 7-52. Disponible en: http://www.scielo.org.mx/scielo.php?pi$\mathrm{d}=\mathrm{S0}$ I 87-0 I 7320 I 200020000 I \&script=sci_abstract.

Weeks, J. (1998). Sexualidad. Buenos Aires: Paidós.

Ziccardi, A. et al. (2020). Condiciones de habitabilidad de las viviendas y del entorno urbano ante el aislamiento social impuesto por el CoVID- 19. Informe preliminar, I I de mayo, México: UNAM, CRIM, UACJ, Universidad de Guadalajara, El Colegio Mexiquense, Colegio de la Frontera Norte, CINVESTAV, IGLOM.

\section{Páginas de Internet}

Gleeden. Disponible en: https://es.gleeden.com/.

Tinder, Disponible en: https://es.wikipedia.org/wiki/Tinder.

La pandemia en México. Disponible en:https://es.wikipedia. org/wiki/Pandemia_de_enfermedad_por_coronavirus_de_2020_en_M\%C3\%A9xico. 